\title{
Social cognition in multiple sclerosis: a meta-analysis
}

Emre Bora $^{1}$, Serkan Özakbaş ${ }^{2}$, Dennis Velakoulis ${ }^{1}$, Mark Walterfang ${ }^{1,3}$

1-Melbourne Neuropsychiatry Centre, Department of Psychiatry, University of Melbourne and Melbourne Health, Carlton South, Victoria 3053, Australia

2-Department of Neurology, Dokuz Eylul University, Balçova, 35340 İzmir, Turkey

3-Florey Department of Neuroscience and Mental Health, University of Melbourne, Parkville 3052, Australia

Running title: Social cognition in MS

Correspondence: Dr Emre Bora

emrebora@hotmail.com,ibora@unimelb.edu.au

Alan Gilbert Building NNF level 3

Carlton 3053, Australia

Phone: 61390358628 Fax: 61393480469

Short title: Social cognition in MS

Keywords: theory of mind; social cognition; emotion recognition; cognitive; Multiple Sclerosis

Word count: 4600 (text-abstract-funding-conflict of interest) 


\section{Funding statement}

This research received no specific grant from any funding agency in the public, commercial or not-for-profit sectors.

\section{Conflict of Interests statement}

Authors have no conflicts of interest regarding subject of this manuscript. Dr. Walterfang reports grants from Actelion pharmaceuticals, personal fees from Actelion pharmaceuticals, personal fees from Orphazyme, outside the submitted work; Dr Ozakbas reports non-financial support from Bayer, Novartis, Merck-Serono and Teva. 


\title{
Social cognition in multiple sclerosis: a meta-analysis
}

\author{
Abstract \\ Multiple sclerosis (MS) is associated with cognitive decline and impairment in social \\ functioning. Accumulating evidence suggests that patients with MS are impaired in social \\ cognition, including theory of mind (ToM) and emotion recognition. In this meta-analysis of \\ 24 studies, facial emotion recognition and ToM performances of 989 patients with MS and \\ 836 healthy controls were compared. MS was associated with significant impairments with \\ medium effect sizes in ToM $(\mathrm{d}=0.57)$ and facial emotion recognition $(\mathrm{d}=0.61)$. Among \\ individual emotions recognition of fear and anger were particularly impaired. The severity of \\ social cognitive deficits was significantly associated with non-social cognitive impairment. \\ These deficits in social cognition may underpin difficulties in social functioning in MS. \\ However, there is a need for further studies investigating the longitudinal evolution of social \\ cognitive deficits and their neural correlates in MS.
}




\section{Introduction}

Multiple sclerosis (MS) is a chronic inflammatory and neurodegenerative disease of the central nervous system characterized by multifocal destruction of myelin sheaths and axonal loss (Compston et al 2002; Geurt and Barkhof, 2008). It is usually diagnosed in young adulthood and its prognosis is variable and unpredictable. MS presents with motor, sensory and other neurological deficits, neuropsychiatric symptoms and cognitive decline (Chiaravalloti and DeLuca 2008; Compston et al 2002; Rosti-Otajärvi and Hämäläinen, 2013; Stroeber et al 2014) leading to significant functional impairment including difficulties in social functioning and employment (Krause et al 2013; Rao et al 1991b).

Cognitive deficits, a common feature of MS, are well studied and can contribute to functional impairment in this condition (Chiaravalloti and DeLuca 2008; Langdon 2011; Rao et al 1991a). Hallmark of neurocognitive impairment in MS is abnormalities in information processing, particularly processing speed (Prakash et al 2008; Van Schependom et al 2014). Other cognitive deficits in MS include impairments in learning and memory, verbal fluency and executive functioning (Prakash et al 2008). Cognitive impairment in MS is detectable from the earliest stages of MS and is generally more evident in progressive types such as secondary progressive (SP) MS (Planche et al 2015). Microstructural abnormalities and lesions in white matter significantly disrupt structural and functional connectivity between various brain regions. Inefficient activity in brain networks caused by these changes contributes to cognitive deficits in MS(Cruz-Gómez et al 2014; Schoonheim et al 2015). However, the aetiology of cognitive deficits in MS are multifactorial: other than white matter pathology, cortical atrophy, cortical lesions, and abnormalities in deep gray matter contribute to cognitive decline in MS (DeLuca et al 2015; Filippi et al 2010). While acute inflammatory relapses can affect cognitive functioning, cognitive decline in MS is usually insidiously progressive (DeLuca et al 2015). Evidence also suggests that cognitive reserve, level of premorbid intellectual development determined by variations in neurodevelopmental processes (i.e genetics, nutrition, physical health) and levels of environmental enrichment (i.e parenting, education, professional and leisure activities), is an important moderator of relationship between cognitive decline and brain pathology in MS (DeLuca et al 2015; Sumowski and Leavitt, 2013). In MS, patients with higher cognitive reserve seem to have less cognitive decline than other patients with similar severity of brain pathology. 
In addition to difficulties in traditional neuropsychological tests, social cognitive impairment has been shown to be a feature of a number of psychiatric and neuropsychiatric disorders (Bora et al 2013; Bora et al 2015a). The recognition of emotions from facial cues is the most commonly studied social cognitive ability. In the human brain, a network of limbic structures that includes the amygdala, insula, orbitofrontal cortex and subcortical structures are activated in response to emotional features in faces (Fusar-Poli et al 2009; Hsieh et al 2012). Another key social cognitive ability is theory of mind (ToM), the ability to attribute mental states (feelings, beliefs, intentions, and desires) to others and understand and predict others' behaviour based on their mental states. Evidence suggests that ToM ability is associated with activation in the medial prefrontal cortex $(\mathrm{mPFC})$ and posterior temporoparietal junction (pTPJ) in response to the very different type of stimuli (Schaafsma et al 2015). ToM is not an entirely homogeneous concept or ability, and ToM tasks differ in the magnitude of cognitive demand, nature of stimuli (emotional vs cognitive mental state) and mode of presentation (verbal versus visual). One important distinction between ToM tasks is whether they measure abilities to use perspective taking (ToM-PT) or decoding (ToM-decoding) based on emotional and perceptual cues to infer others' thoughts, beliefs, emotions. ToM-PT, which was also called as mental state reasoning (Sabbagh, 2004), is most typically assessed by tasks measuring false belief and indirect speech comprehension. The Reading of the mind in the eyes test (RMET) is the most commonly used task to assess ToM-decoding (Baron-Cohen et al; Sabbagh et al 2004). Evidence also suggests that there are some differences in the neural network involved in different aspects of ToM. Beyond common activations in the core network of mPFC and pTPJ, there are considerable activation differences in neighboring and other more distant brain regions depending on the task used (Schaafsma et al 2015).

Social cognitive deficits, including impairment in emotion recognition and ToM, may be clinically relevant impairments for MS patients as effective and adaptive social functioning depends critically on social cognition and MS is associated with significant psychosocial impairment including difficulties in employment and interpersonal domains (Krause et al 2013; Rao et al 1991b). Subtle difficulties in recognizing others' emotional expressions, empathic abilities, reading their complex mental states and understanding pragmatic language statements (such as irony) can contribute to interpersonal problems observed in MS. Evidence also suggests that MS patients might also subjectively report difficulties in recognizing their own emotions and empathy (Chahraoui et al 2014; Gleichgerrcht et al 2015). White and gray matter pathology in MS affects multiple brain regions and disrupts a 
number of neural networks that play key roles in social cognition. However, neuropsychological studies in MS have only recently started to focus on social cognitive deficits. These studies have provided some evidence of impairment in social cognition including ToM and emotion recognition abilities in MS (Berneiser et al 2014; Cecchetto et al 2014; Pöttgen et al 2013; Roca et al 2014). However, a number of studies have failed to find such deficits, especially for emotion recognition (Di Bitonto et al 2011; Jehna et al 2010; Jehna et al 2011). Currently, the severity of social cognitive deficits in comparison to other neuropsychological difficulties is not clear, and it is not known whether recognition of some emotions or different aspects of ToM are differentially impaired in MS. The primary goal of this meta-analysis was to quantify the magnitude of social cognitive deficits, to examine if some aspects of social cognition are relatively more impaired in MS than others, and to explore the relationship between social cognitive impairment and other clinical variables in MS.

\section{Methods}

\section{Study selection}

We followed MOOSE and PRISMA guidelines in conducting this meta-analysis (Moher et al 2009; Stroup et al 2000). A literature search was conducted using the databases Pubmed, PsycINFO, ProQuest and Scopus to identify the relevant studies (January 1998 to September 2015) using the combination of keywords as follows: (Theory of mind or emotion recognition or social cognition) and multiple sclerosis. Reference lists of published reports were also reviewed for additional studies and Google Scholar was to retrieve unpublished material including conference papers and theses. Inclusion criteria were studies that: (1) Compared ToM or facial emotion recognition performances of MS and healthy controls; (2) reported sufficient data to calculate the effect size and standard error of the social cognition measure. Two brain imaging studies (Krause et al. 2009; Mike et al. 2013) and a thesis whose samples overlap with two included study (Banati et al. 2010; Berneiser et al 2014) were excluded. We contacted authors of two conference papers for unpublished data or papers but we were unable to ascertain this data. Studies investigating emotion recognition abilities with methods other than facial recognition were excluded as only a few studies investigated MS using such methods (i.e. vocal).

Figure-1 Flow Diagram for meta-analysis of social cognition deficits in MS (Approximately here)

\section{Social cognition measures}


Studies have investigated facial emotion recognition with a variety of methods (different sets of images of faces to label: most commonly Ekman) (Ekman and Friesen, 1976). Different ToM tasks have been utilized across studies, most commonly faux pas recognition (the task involves recognizing faux pas in series of short stories) and Reading the Mind in the Eyes Task (RMET); other tasks have included Happe stories and different versions of false belief and intention tasks (Baron-Cohen et al 2001; Stone et al 1998). In RMET, individuals are instructed to look at a series of photographs of just the eye region of the face, and picking which of four words best describe what the person in the photo is thinking or feeling. RMET was the only measure for ToM-decoding. All other ToM tasks were measuring ToM-PT.

\section{Statistical analyses}

For studies that reported more than one ToM task, pooled effect sizes and standard error values were calculated. A pooled effect size of social cognition based on ToM and/or total emotion recognition score was calculated for each study. Individual tasks analyses for two ToM measures (RMET, faux pas recognition) were also possible. A pooled effect size of ToM-PT was also calculated by averaging effect size of ToM tasks other than RMET. In addition to the total emotion labeling score, separate effect sizes for six basic emotions (anger, fear, disgust, sadness, happiness, surprise) were also calculated. An additional analysis of facial emotion recognition was conducted to calculate mean effect size of studies that used Ekman stimuli.

Meta-analyses were performed using packages in the R environment (OpenMetaAnalyst, Metafor) and MIX software version 1.7 on a Windows platform (Bax et al 2006; Viechtbauer , 2010; Wallace et al 2012). Effect sizes were weighted using the inverse variance method. Several studies included subgroups of MS and shared control groups (Brandon, 2015; Dulau, 2014; Ouellet et al 2010; Radlak, 2014) (See Table 1). Therefore, we divided $n$ of control groups between comparisons not to overestimate the contribution of these studies to overall effect size. A random effects model (DerSimonian-Laird estimate) was used. Homogeneity of the distribution of weighted effect sizes was tested with the $\mathrm{Q}$ and $\mathrm{I}^{2}$ tests. Tau-squared $\left(\tau^{2}\right)$, an estimate of between-study variance, was used as a measure of heterogeneity in the random effects model. Publication bias was assessed by inspection of funnel plots, Egger's test and trim and fill method. Egger's test relies on the theory that small studies with significant rather than negative findings in studies with small sample sizes would be more likely to be reported while large-scale studies would be more likely to be published regardless 
of the significance of the findings. The significance threshold of Egger's test was defined as $\mathrm{p}=0.1$ due to small numbers of studies included in some analyses.

Subgroup analyses were conducted for age (matched vs non-matched), gender (matched vs non-matched), duration of education (matched vs non-matched), depressive symptoms (No difference vs significantly increased in MS), MS severity based on EDSS (Expanded Disability Status Scale) (Mild/moderate only (EDSS cut off score 4.5 or 5) vs also includes patients with more severe symptoms), and neurocognition (impaired vs non-impaired). Cognitive impairment was defined as having a severe impairment (Cohen's $d>0.8$ ) in comparison to healthy controls in at least one measure or having a medium-sized impairment (Cohen's d $>0.5$ ) of pooled effect size of all cognitive tests used (Table-1). Qbet test was used to statistically compare subgroups in these analyses. Meta-regression analyses were conducted for gender (ratio of females in MS group) with a random effects model were using the restricted-information maximum likelihood method with a significance level set at $\mathrm{p}<0.05$. Other than the main meta-analysis, separate meta-analyses for social cognition $(\mathrm{k}=11)$, ToM $(\mathrm{k}=7)$ and facial emotion recognition $(\mathrm{k}=7)$ were conducted in studies that included only RR type MS. We also repeated the main meta-analysis of social cognition after removing 4 theses/conferences papers included. Also, a preliminary comparison of RR and chronic progressive types of MS were conducted for social cognition $(\mathrm{k}=5)$.

Figure-2 Forest plot for facial emotion recognition differences between MS and healthy controls: Diamond shape $=$ average effect size and its confidence interval based on random effects model; $\mathrm{SE}=$ Standard error of Cohen's d

(Approximately here)

\section{Results}

Twenty-four studies (29 MS-healthy controls comparisons) involving 989 (69.3\% females) MS patients and 836 (62.1\% females) healthy controls were included (Table 1) (see Figure 1 for the flow chart of the study selection process). There was a significant but very modest difference for age; individuals with MS tended to be older than healthy controls ( $d=0.16$, $\mathrm{CI}=0.0-0.31, \mathrm{p}=0.05, \mathrm{k}=29)$. In 11 samples, all MS patients were relapsing-remitting (RR) type and other 7 studies, MS patients were predominantly RR type. Two study sample included only secondary progressive (SP) MS, one sample included chronic progressive subtypes (mostly SP) of MS and another sample included only primary progressive (PP) type MS. Other studies had mixed samples. Only one of the studies included patients with 
clinically isolated syndrome (CIS) and none of the studies included patients with radiologically isolated syndrome (RIS). In four studies, social cognitive abilities of RR and chronic progressive (SP and/or PP) types of MS were compared.

Social cognition was significantly impaired $(d=0.56, \mathrm{CI}=0.42-0.69, \mathrm{k}=29)$ in MS in comparison to healthy controls (Table-2 and Supplement 1). The severity of impairment in social cognition was similar when 4 non-peer reviewed (theses and a conference paper) studies were excluded $\left(\mathrm{d}=0.60, \mathrm{CI}=0.43-0.77, \mathrm{Z}=7.0, \mathrm{p}<0.001, \tau^{2}=0, \mathrm{k}=21\right)$. In separate analyses of the two key social cognitive domains investigated, the performance of MS patients was significantly poorer than healthy controls for both emotion recognition $(d=0.61$, $\mathrm{CI}=0.39-0.83, \mathrm{k}=17$, Figure-2) and ToM ( $d=0.57, \mathrm{CI}=0.42-0.73, \mathrm{k}=19$, Figure-3) (Table-2). Distribution of effect sizes for ToM was homogeneous ( $\mathrm{p}$ for $\mathrm{Q}=0.09, \mathrm{I}^{2}=32 \%, \tau^{2}=0.04$ ) but there was a significant but moderate heterogeneity for facial emotion recognition ( $\mathrm{p}$ for $\mathrm{Q}<0.001, \mathrm{I}^{2}=64 \%, \tau^{2}=0.14$ ) (Table-2). In the subgroup analysis of studies using Ekman pictures as facial emotion stimuli, MS patients underperformed healthy controls and distribution of effect sizes were homogeneous $(\mathrm{d}=0.74, \mathrm{CI}=0.54-0.94, \mathrm{Z}=7.4, \mathrm{p}<0.001$, $\left.\tau^{2}=0.01\right)$.

In the analysis of individual emotions, MS patients significantly underperformed controls in all emotions (Table 2 and Supplement 1). The severity of deficits was relatively pronounced for recognition of fear $(d=0.54, \mathrm{CI}=0.34-0.73, \mathrm{k}=9)$ and anger $(d=0.56, \mathrm{CI}=0.32-0.80, \mathrm{k}=10)$ (Supplement 1). Effect sizes for sadness $(d=0.32, \mathrm{CI}=0.16-0.49, \mathrm{k}=9)$, disgust $(d=0.25$, $\mathrm{CI}=0.01-0.50, \mathrm{k}=9)$, surprise $(d=0.32, \mathrm{CI}=0.12-0.52, \mathrm{k}=8)$ and happy $(d=0.22, \mathrm{CI}=0.04-0.39$, $\mathrm{k}=9$ ) face stimuli indicated significant but small sized deficits (Table-2). It was possible to conduct individual analyses for two ToM tasks. There was significant impairment in RMET $(d=0.67, \mathrm{CI}=0.47-0.88, \mathrm{k}=10)$ and ToM-PT $(d=0.39, \mathrm{CI}=0.17-0.61, \mathrm{k}=14)$; however, while MS patients tended to underperform healthy controls in faux pas recognition between-group difference was not significant $(d=0.25, \mathrm{CI}=-0.04-0.55, \mathrm{k}=9, \mathrm{p}=0.08$ ) (Table-2 and Supplement 1). Distribution of effects sizes for RMET and four of the six basic emotions were homogenous, but there was significant but modest heterogeneity for faux pas recognition $\left(\mathrm{I}^{2}=\right.$ $55 \%, \tau^{2}=0.11$ ), recognition of anger ( $\mathrm{p}$ for $\left.\mathrm{Q}=0.03, \mathrm{I}^{2}=51 \%, \tau^{2}=0.07\right)$ and disgust $\left(\mathrm{I}^{2}=48 \%\right.$, $\left.\tau^{2}=0.06\right)$ (Table-2). Egger's tests, trim and fill method (Table-2) and inspection of funnel plots (See Supplement 2) did not provide evidence of publication bias for any of the measures. 
Figure-3 Forest plot for ToM differences between MS and healthy controls

(Approximately here) ----------

MS subtypes and social cognition

In studies that included only RR MS, social cognition was significantly impaired $(d=0.53$, $\left.\mathrm{CI}=0.34-0.71, \mathrm{Z}=5.5, \mathrm{p}<0.001, \tau^{2}=0.02, \mathrm{k}=10\right)$. In separate analysis of social cognitive domains, RR-MS patients were significantly impaired both in ToM (d=0.48, CI=0.29-0.66, $\left.\mathrm{Z}=5.0, \mathrm{p}<0.001, \tau^{2}=0, \mathrm{k}=7\right)$ and facial emotion recognition $(\mathrm{d}=0.59, \mathrm{CI}=0.29-0.90, \mathrm{Z}=3.6$, $\mathrm{p}<0.001, \tau^{2}=0.12, \mathrm{k}=8$ ). In a preliminary analysis for the comparison of chronic progressive and RR-MS ( $\mathrm{k}=5)$, social cognition was tended to be more impaired in chronic progressive MS in comparison to RR MS (d=0.42, $\mathrm{CI}=-0.06-0.91, \mathrm{Z}=1.7, \mathrm{p}=0.08, \mathrm{Q}=1.2, \mathrm{p}$ for $\mathrm{Q}=0.02$, $\left.\mathrm{I}^{2}=67 \%, \tau^{2}=0.20\right)($ Supplement 1$)$.

\section{Effect of confounding variables}

In subgroup analyses, the severity of social cognitive impairment in patients that were matched for age to control group was similar to patients who were not matched to control group (Table-3). Same was also true for the duration of education. Impairment in social cognition in MS patients who were more depressed than controls group was not statistically different from impairment in MS patients that were matched to control group for depressive symptoms. There was no significant difference in severity of social cognitive impairment between MS samples that only included patients with mild or moderate severity and samples that included MS patients with more severe disability. MS patients who had severe non-social cognitive impairment had a more severe social cognitive deficit in comparison to other patients (Table-3). Meta-regression analysis did not find significant relationship between ratio of females in MS group and deficits in social cognition $(Z=0.14, p=0.89)$.

\section{Discussion}

The current meta-analysis investigated social cognitive deficits in MS in comparison with healthy controls. Our findings showed that MS patients significantly underperformed healthy controls in ToM and facial emotion recognition tasks. Non-social cognitive impairment was significantly associated with social cognitive deficits.

In the current meta-analysis, medium effect sizes were found for ToM $(d=0.57)$ and facial emotion recognition $(d=0.61)$ deficits in MS. Severity of these deficits were much less pronounced than impairments reported for number of neurodegenerative conditions predominantly characterized by severe cortical and subcortical gray matter atrophy such as 
FTD and Huntington's disease (Bora et al 2015a; Bora et al 2016), however, these findings still suggest that many patients with MS have significant difficulties in emotion recognition and ToM. Current findings suggest that social cognitive impairment, such as the poor reading of others' intentions and a key difficulty in recognition of anger and fear can potentially contribute to psychosocial and interpersonal difficulties observed in MS.

The severity of impairment in social cognition was comparable in magnitude to most nonsocial cognitive deficits as reported in previous meta-analyses in MS, which have reported small to medium effect sizes for most cognitive variables (Henry and Beatty 2006; Prakash et al 2008). Effects sizes for impairments in ToM and facial emotion recognition were very similar to the severity of most deficits in non-social cognitive tasks including general cognition, executive functions relatively larger ( $g=0.54-0.59)$ (Prakash et al 2008). Both decoding and reasoning aspects of ToM were impaired in MS. RMET was more sensitive than faux pas recognition in detecting mentalizing problems in MS. Emotion recognition deficits were relatively specific to fear and anger. Effect sizes of deficits in other four emotions indicated mild impairment. Also, unlike other neurodegenerative conditions, deficits in recognition anger and fear were not accompanied by severe difficulties in recognition of disgust (Bora et al 2015a; Bora et al 2016). Relative specificity of deficits in recognition of some negative emotions (anger and fear) is interesting as MS is characterized by widespread rather than focal brain abnormality. Interestingly, a similar pattern of relatively specific impairment in recognition of fear and anger has been a consistent finding in pediatric ADHD studies (Bora and Pantelis, 2015). While MS and ADHD (and associated social cognitive deficits) have very different etiologies (demyelinating/neurodegenerative $v s$. maturational) and outcomes (deterioration vs. improvement by time), both conditions share some characteristics such as information processing deficits and negative effects on the efficiency of intrinsic brain networks (Sripada et al 2014). These findings speculatively suggest the possibility that pattern of social cognitive deficits might be different in maturational or neurodegenerative conditions mainly affecting white matter integrity or functional connectivity in comparison to neurodegenerative diseases predominantly associated with loss of gray matter integrity in frontotemporal and subcortical regions. However, further work is necessary to distinguish different patterns of social cognitive deficits associated with different neuropsychiatric disorders. Also, the relatively mild deficit in recognition of happiness is not specific to MS and is common finding across different neuropsychiatric disorders. Task difficulty might play a role in the relatively good performance of recognition of happy emotions and poor performance in some negative 
emotions across disorders (Rosenberg et al 2014). Positive emotions other than recognition of happiness have been rarely used in neuropsychological research in neurological disorders. Studies using more complex positive emotional stimuli can potentially reveal more severe recognition deficits in MS.

Social cognitive deficits observed in this meta-analysis were not significantly related to depressive symptoms or physical disability, as measured by EDSS, in MS samples. These findings suggest that social cognitive impairment observed in MS is not simply caused by low mood and physical disability. However, it is important to note that most individuals with MS in included studies did not meet criteria for clinical depression, it might be expected that social cognitive, especially ToM, deficits could be exacerbated during depression - as is seen in subjects without neurological disorders (Bora and Berk, 2016). It is also not known if impairments in insight and neuropsychiatric symptoms such as apathy, euphoria, aggression which are observed in some patients with MS - are related to social cognitive deficits, as these have not been extensively explored in this disorder. The lack of association between physical disability (as measured by EDSS) and social cognition is not surprising as EDSS has only one item which assesses cognition (subjectively) and higher scores mainly reflect problems in mobility. For example, patients with lesions mainly affecting the spinal cord and pyramidal tracts could have very high scores in EDSS without much evidence of cognitive deficits. Future studies including other measures of physical disability, such as Multiple Sclerosis Functional Composite (MSFC), might show better correlations between the level of physical disability and impairments in social functioning and social cognition (Hanken et al 2015). We were not able to investigate the effect fatigue, another important potential moderator on social cognitive performance in MS, due to lack of social cognition studies reporting this variable. Previous studies have shown that MS-related fatigue is associated with poor performance in tasks assessing vigilance (Bora et al 2015b) and effects of fatigue on social cognition should be investigated further. Another consideration is the effect of subtypes of MS on social cognitive deficits. Our findings in RR type of MS suggested that social cognitive deficits are evident in non-progressive MS. Only four studies have compared performances of RR and chronic progressive types of MS. While three of these studies reported more severe deficits in SP compared to RR type (Berneiser et al 2014; Brandon, 2015; Radlak, 2014), between-group differences were not significant in the fourth study (Dulau, 2014). A preliminary meta-analysis of these four studies suggested that social 
cognition is tended to be more impaired in chronic progressive than RR MS. In MS studies, among potential proxy measures of cognitive reserve (premorbid IQ, employment, parental measures and education), duration of education is the most commonly used measure. In previous neurocognitive and brain imaging studies in MS, duration of education was shown to be a significant moderator. In the current meta-analysis, differences for duration education (patients vs. controls) was not associated with social cognitive differences between MS and healthy controls. This finding suggests that duration of education is the not the best proxy measure for premorbid social cognitive abilities. Measures assessing premorbid social functioning can be expected to reflect premorbid social cognition better and should be considered to be included in future studies investigating social cognition in MS.

Neurocognitive impairment in MS was significantly associated with more severe social cognitive deficits. These findings are in line with previous findings in other neuropsychiatric disorders including Huntington's disease and frontotemporal dementia (Bora et al 2015a; Bora et al 2015c). Non-social cognitive impairment including attention, executive dysfunction and perceptual abnormalities (i.e. face recognition) can contribute to social cognitive impairment in MS. Impairment in social cognition in MS is likely to be multifactorial, with non-specific (cognitive impairment, fatigue) and specific (i.e. abnormalities in brain regions involved in social cognition) factors playing a role. Few studies have directly investigated the relationship between brain imaging abnormalities and social cognition in MS. Mike et al (2013) reported that disconnection between cortical regions involving the processing of emotions and socially relevant information can be related to deficits in facial emotion recognition in MS. This study also reported an association between cortical atrophy (temporal and prefrontal cortices) and performance in RMET but not in faux pas recognition. In another study, Krause et al (2009) found that poor performance in recognition of unpleasant emotions (anger, fear and sadness) was related to less activation in the insula and ventrolateral prefrontal cortex. However, in MS patients who differ from controls in behavioral performance, Passamonti et al (2009) reported increased ventrolateral prefrontal cortex activation but also decreased functional connectivity between frontal cortex and the amygdala. In a fourth study, Jehna et al (2011) found increased activation in the posterior cingulate cortex and precuneus for anger and disgust in MS patients who have not behaviorally performed poorer than healthy controls. There is a need for further investigation into the neural correlates that underpin these deficits, to elucidate the neurobiological mechanisms of ToM and emotion recognition deficits in MS. 
Effects of currently available disease-modifying treatments of MS on delaying social cognitive deficits are not known. However, there is some evidence suggesting positive effects of these treatments on cognitive deficits (Lyros et al 2010) and same can be expected for social cognition. Early psychopharmacological interventions may have the potential to delay social cognitive deficits and the resultant disability in social and vocational functioning. Some evidence also suggests that cognitive rehabilitation can - at least partially - remediate cognitive deficits in MS (Mitolo et al 2015) and future studies may consider incorporating social cognition in training programs to improve social functioning in MS.

There are a number of limitations to our meta-analysis. We were not able to investigate emotion recognition deficits beyond facial stimuli. However, preliminary evidence suggests that MS is also associated with deficits in recognition of non-facial stimuli including vocal prosody and body language (Beatty et al 2003; Cecchetto et al 2014; Kraemer et al 2013). The heterogeneity of social and cognition measures was another limitation. To overcome this limitation, we conducted individual task analysis when possible. Another consideration is psychometric limitations of social cognition tasks in comparison to traditional neuropsychological batteries (Johnston et al 2008). There is a need for further development of standardized batteries for assessment of social cognition in neuropsychiatric disorders. Heterogeneity of the samples such as differences in duration of illness, demographic characteristics, depressive symptoms across studies and inclusion of varying proportions of individuals with different subtypes of MS. Therefore, we conducted a number of subgroup analyses. Also, available studies have focused on RR and chronic progressive subtypes of MS. There is a need for studies investigating social cognition in RIS and CIS. Another limitation was that a relatively smaller number of studies was included in the meta-analysis of individual emotions.

In conclusion, our findings suggest that MS is associated with significant deficits in social cognition. The severity of these impairments is relatively modest (medium effect sizes) but comparable to other cognitive deficits in MS. Social cognitive impairment is likely to contribute to poorer social functioning in many individuals with MS. Future studies investigating the course of social cognitive deficits, and studies further exploring the neural correlates of these impairments in MS are necessary. 


\section{Funding statement}

This research received no specific grant from any funding agency in the public, commercial or not-for-profit sectors.

\section{Competing Interests statement}

Authors have no conflicts of interest regarding subject of this manuscript. Dr. Walterfang reports grants from Actelion pharmaceuticals, personal fees from Actelion pharmaceuticals, personal fees from Orphazyme, outside the submitted work; Dr Ozakbas reports non-financial support from Bayer, Novartis, Merck-Serono and Teva. 


\section{References}

Banati, M., Sandor, J., Mike, A., et al (2010). Social cognition and Theory of Mind in patients with relapsing-remitting multiple sclerosis. European Journal of Neurology 17, 42633.

Baron-Cohen, S., Wheelwright, S., Hill, J., Raste, Y., Plumb, I (2001). The Reading the Mind in the Eyes"' test revised version: a study with normal adults, and adults with Asperger syndrome or high-functioning autism. Journal of Child Psychology and Psychiatry 42, 241251.

Bax, L., Yu, L.M., Ikeda, N., Tsuruta, H., Moons, K.G (2006). Development and validation of MIX: comprehensive free software for meta-analysis of causal research data. BMC Medical Research Methodology 6, 50

Beatty, W.W., Goodkin, D.E., Weir, W.S., (1989) et al. Affective judgments by patients with Parkinson's disease or chronic progressive multiple sclerosis. Bulletin of Psychonomic Society 1989 ;27: 361-364.

Beatty, W.W., Orbelo, D.M., Sorocco, K.H., Ross, E.D (2003). Comprehension of affective prosody in multiple sclerosis. Multiple Sclerosis 9, 148-53.

Berneiser, J., Wendt, J., Grothe, M., Kessler, C., Hamm, A.O., Dressel, A (2014). Impaired recognition of emotional facial expressions in patients with multiple sclerosis.

Multiple Sclerosis and Related Disorders 3, 482-8.

Bora, E., Eryavuz, A., Kayahan, B., Sungu, G., Veznedaroglu, B (2006). Social functioning, theory of mind and neurocognition in outpatients with schizophrenia; mental state decoding may be a better predictor of social functioning than mental state reasoning. Psychiatry

Research 145, 95-103.

Bora, E., Pantelis, C (2013). Theory of mind impairments in first-episode psychosis, individuals at ultra-high risk for psychosis and in first-degree relatives of schizophrenia: systematic review and meta-analysis. Schizophrenia Research 144, 31-6 Bora, E., Walterfang, M., Velakoulis, D (2015a). Theory of mind in behavioural-variant frontotemporal dementia and Alzheimer's disease: a meta-analysis. Journal of Neurology, Neurosurgery and Psychiatry 86, 714-9.

Bora, E., Walterfang, M., Velakoulis, D (2015b). Theory of mind in Parkinson's disease: A meta-analysis. Behavioral Brain Research 292, 515-520.

Bora, E., Velakoulis, D., Walterfang, M (2016). Social cognition in Huntington's disease. Behavioral Brain Research 297, 131-140

Bora, E., Berk, M (2016). Theory of mind in major depressive disorder: A meta-analysis.

Journal of Affective Disorders 191, 49-55.

Brandon, L.R (2015).Theory of mind in multiple sclerosis:Disease subtype differences and association with measures of social functioning. University of Missouri-Kansas City (thesis) 
Cecchetto, C., Aiello, M., D'Amico, D., et al (2014). Facial and bodily emotion recognition in multiple sclerosis: the role of alexithymia and other characteristics of the disease. Journal of International Neuropsychological Society 20, 1004-14.

Chahraoui, K., Duchene, C., Rollot, F., Bonin, B., Moreau, T (2014). Longitudinal study of alexithymia and multiple sclerosis. Brain and Behaviour 4, 75-82.

Charvet, L.E., Cleary, R.E., Vazquez, K., Belman, A.L., Krupp, L.B; US Network for Pediatric MS (2014). Social cognition in pediatric-onset multiple sclerosis (MS). Multiple Sclerosis 20, 1478-84.

Chiaravalloti, N.D., DeLuca, J (2008). Cognitive impairment in multiple sclerosis. Lancet Neurology 7, 1139-1151.

Compston, A., Coles, A (2002). Multiple sclerosis. Lancet 359(9313), 1221-1231

Cruz-Gómez, Á.J., Ventura-Campos, N., Belenguer, A., Ávila, C., Forn, C (2014). The link between resting-state functional connectivity and cognition in MS patients. Multiple Sclerosis 20, 338-48.

DeLuca, G.C., Yates, R.L., Beale, H., Morrow, S.A (2015). Cognitive impairment in multiple sclerosis: clinical, radiologic and pathologic insights. Brain Pathology 25, 79-98.

Di Bitonto, L., Longato, N., Jung, B., et al (2011). [Reduced emotional reactivity to negative stimuli in multiple sclerosis, preliminary results]. Revue neurologique (Paris), 167, 820-6.

Dulau, C (2014). Existe-t-il vraiment une atteinte de la cognition sociale dans la scl'erose en plaques? Human health and pathology <dumas-01089147> (Thesis Bordeaux University) http//dumas.ccsd.cnrs.fr/dumas-01089147

Ekman, P., Friesen, W (1976). Pictures of facial affect. Consulting Psychologists Press, Palo Alto, CA

Filippi, M., Rocca, M.A., Benedict, R.H., et al (2010). The contribution of MRI in assessing cognitive impairment in multiple sclerosis. Neurology 75, 2121-2128.

Fusar-Poli, P., Placentino, A., Carletti, F., et al (2009). Functional atlas of emotional faces processing: a voxel-based meta-analysis of 105 functional magnetic resonance imaging studies. Journal of Psychiatry and Neuroscience 34, 418-32.

Geurts, J.J.G., Barkhof, F (2008). Grey matter pathology in multiple sclerosis. Lancet Neurology 7, 841-851

Gleichgerrcht, E., Tomashitis, B., Sinay, V (2015). The relationship between alexithymia, empathy and moral judgment in patients with multiple sclerosis. European Journal of Neurology

22, 1295-303.

Hanken, K., Eling, P., Hildebrandt, H (2015). Is there a cognitive signature for MS-related fatigue? Multiple Sclerosis 21, 376-81.

Henry, J.D., Beatty, W.W (2006). Verbal fluency deficits in multiple sclerosis.

Neuropsychologia 44, 1166-74

Henry, J.D., Phillips, L.H., Beatty, W.W., et al (2009). Evidence for deficits in facial affect recognition and theory of mind in multiple sclerosis. Journal of International Neuropsychological Society 15, 277-85. 
Henry, A., Tourbah, A., Chaunu, M.P., Rumbach, L., Montreuil, M., Bakchine, S (2011). Social cognition impairments in relapsing-remitting multiple sclerosis. Journal of International Neuropsychological Society 17, 1122-31

Hsieh, S., Hornberger, M., Piguet, O., Hodges, J.R (2012). Brain correlates of musical and facial emotion recognition: evidence from the dementias. Neuropsychologia 50 ,1814-22. Jehna, M., Neuper, C., Petrovic, K., et al (2010). An exploratory study on emotion recognition in patients with a clinically isolated syndrome and multiple sclerosis. Clinical Neurology and Neurosurgery 112, 482-4.

Jehna, M., Langkammer, C., Wallner-Blazek, M., et al (2011). Cognitively preserved MS patients demonstrate functional differences in processing neutral and emotional faces. Brain Imaging and Behaviour 5, 241-51.

Johnston L., Miles L., McKinlay A. (2008). A critical review of the eyes test as a measure of social-cognitive impairment. Aust. J. Psychol. 60, 135-141

Kraemer, M., Herold, M., Uekermann, J. et al (2013a). Theory of mind and empathy in patients at an early stage of relapsing remitting multiple sclerosis. Clinical Neurology and Neurosurgery 115, 1016-22.

Kraemer, M., Herold, M., Uekermann, J., et al (2013b). Perception of affective prosody in patients at an early stage of relapsing-remitting multiple sclerosis. Journal of Neuropsychology 7, 91-106.

Krause, M., Wendt, J., Dressel, A., Berneiser, J., Kessler, C., Hamm, A.O., et al (2009).

Prefrontal function associated with impaired emotion recognition in patients with multiple sclerosis. Behavioral Brain Research 205, 280-5.

Krause, I., Kern, S., Horntrich, A., Ziemssen, T (2013). Employment status in multiple sclerosis: impact of disease-specific and non-disease-specific factors. Multiple Sclerosis 19, 1792-9.

Langdon, D.W (2011). Cognition in multiple sclerosis. Current Opinion in Neurology 24, 244-249.

Lenne, B., Barthelemy, R., Nandrino, J.L., et al (2014). Impaired recognition of facial emotional expressions in multiple sclerosis. Neuropsychological Trends 15, 67-83.

Lyros, E., Messinis, L., Papageorgiou, S.G., Papathanasopoulos, P. Cognitive dysfunction in multiple sclerosis: the effect of pharmacological interventions. International Review of Psychiatry 2010;22: 35-42

Mike, A., Strammer, E., Aradi, M., Orsi, G., Perlaki, G., Hajnal, A., et al (2013).

Disconnection mechanism and regional cortical atrophy contribute to impaired processing of facial expressions and theory of mind in multiple sclerosis: a structural MRI study. PLoS One 8, e82422.

Mitolo, M., Venneri, A., Wilkinson, I.D., Sharrack, B (2015). Cognitive rehabilitation in multiple sclerosis: A systematic review. Journal of Neurological Sciences 354, 1-9.

Moher, D., Liberati, A., Tetzlaff, J., Altman, D.G., Group PRISMA (2009). Preferred reporting items for systematic reviews and meta-analyses: the PRISMA statement. BMJ 339, b2535.

Ouellet, J., Scherzer, P.B., Rouleau, I., et al (2010). Assessment of social cognition in patients with multiple sclerosis. Journal of International Neuropsychological Society 16,287 96. 
Passamonti, L., Cerasa, A., Liguori, M., Gioia, M.C., Valentino, P., Nisticò, R., et al (2009). Neurobiological mechanisms underlying emotional processing in relapsing-remitting multiple sclerosis. Brain 132, 3380-91.

Phillips, L.H., Henry, J.D., Scott, C., Summers, F., Whyte, M., Cook, M (2011). Specific impairments of emotion perception in multiple sclerosis. Neuropsychology 25, 131-6

Pinto, C., Gomes, F., Moreira, I., et al (2012). Emotion recognition in multiple sclerosis. $J$ Eye Track, Visual Cognition \& Emotion 2, 76-81.

Planche, V., Gibelin, M., Cregut, D., Pereira, B., Clavelou, P (2015). Cognitive impairment in a population-based study of patients with multiple sclerosis: differences between late relapsing-remitting, secondary progressive and primary progressive multiple sclerosis. European Journal of Neurology (in press) doi: 10.1111/ene.12715.

Pöttgen, J., Dziobek, I., Reh, S., Heesen, C., Gold, S.M (2013). Impaired social cognition in multiple sclerosis. Journal of Neurology Neurosurgery and Psychiatry 84, 523-8.

Prakash, R.S., Snook, E.M., Lewis, J.M., Motl, R.W., Kramer, A.F (2008). Cognitive impairments in relapsing-remitting multiple sclerosis: a meta-analysis. Multiple Sclerosis 14, 1250-61.

Prochnow, D., Donell, J., Schäfer, R., et al (2011). Alexithymia and impaired facial affect recognition in multiple sclerosis. Journal of Neurology 258, 1683-8

Radlak, B. (2014). Social cognition in Multiple Scleoris. Effects of social participation and quality of life. University of Aberdeen (Thesis)

Rao, S.M., Leo, G.J., Bernardin, L., Unverzagt, F (1991a). Cognitive dysfunction in multiple sclerosis. I. Frequency, patterns, and prediction. Neurology 41, 685691.

Rao, S.M., Leo, G.J., Ellington, L., Nauertz, T., Bernardin, L., Unverzagt, F (1991b). Cognitive dysfunction in multiple sclerosis. II. Impact on employment and social functioning. Neurology 41, 692-6.

Roca, M., Manes, F., Gleichgerrcht, E., et al (2014). Cognitive but not affective theory of mind deficits in mild relapsing-remitting multiple sclerosis. Cognitive and Behavioral Neurology 27, 25-30.

Rosenberg H, McDonald S, Dethier M, Kessels RP, Westbrook RF. Facial emotion recognition deficits following moderate-severe Traumatic Brain Injury (TBI): re-examining the valence effect and the role of emotion intensity. J Int Neuropsychol Soc. 2014;20:9941003.

Rosti-Otajärvi, E., Hämäläinen, P (2013). Behavioural symptoms and impairments in multiple sclerosis: a systematic review and meta-analysis. Multiple Sclerosis 19, 31-45. Sabbagh, M.A (2004). Understanding orbitofrontal contributions to theory-of-mind reasoning: implications for autism. Brain and Cognition 55, 209-19.

Sabbagh, M.A., Moulson, M.C., Harkness, K.L (2004). Neural correlates of mental state decoding in human adults: an event-related potential study. Journal of Cognitive Neuroscience 16, 415-26. 
Schaafsma, S.M., Pfaff, D.W., Spunt, R.P., Adolphs, R (2015). Deconstructing and reconstructing theory of mind. Trends in Cognitive Science 19, 65-72.

Schoonheim, M.M., Meijer, K.A., Geurts, J.J (2015). Network collapse and cognitive impairment in multiple sclerosis. Frontiers in Neurology 6, 82.

Sripada, C.S., Kessler, D., Angstadt, M (2014). Lag in maturation of the brain's intrinsic functional architecture in attention-deficit/hyperactivity disorder. PNAS US A 111, 14259-64.

Stone, V.E., Baron-Cohen, S., Knight, R.T (1998). Frontal lobe contributions to theory of mind. Journal of Cognitive Neuroscience 10, 640-656.

Strober, L.B., Rao, S.M., Lee, J.C., Fischer, E (2014). Rudick, R. Cognitive impairment in multiple sclerosis: An 18 year follow-up study. Multiple Sclerosis and Related Disorders 3, 473-81.

Stroup, D.F., Berlin, J.A., Morton, S.C., et al (2000). Meta-analysis of observational studies in epidemiology: a proposal for reporting. Meta-analysis Of Observational Studies in Epidemiology (MOOSE) group. JAMA 283, 2008-12.

Sumowski, J.F., Leavitt, V.M (2013). Cognitive reserve in multiple sclerosis. Multiple Sclerosis 19, 1122-7.

Van Schependom, J., D'hooghe, M.B., Cleynhens, K., et al (2014). The Symbol Digit Modalities Test as sentinel test for cognitive impairment in multiple sclerosis. European Journal of Neurology 21, 1219-25, e71-2.

Vanotti, S., Rojas, G., Allegri, R., Caceres, F., RELACCEM work group (2012). How Behavioral and Quality of Life Changes Affect Social Cognition in Multiple Sclerosis Patients. Neurology 178, P02.042

Viechtbauer, W (2010). Conducting meta-analyses in R with the metafor package. Journal of Statistical Softwares 36; 1-48

Wallace, B.C., Dahabreh, I.J., Trikalinos, T.A., Lau, J., Trow, P., Schmid, C.H (2012). Closing the Gap between Methodologists and End-Users: R as a Computational Back-End. Journal of Statistical Softwares 49, 1-15 
Figure 1-Flow Diagram for meta-analysis of social cognition deficits in MS
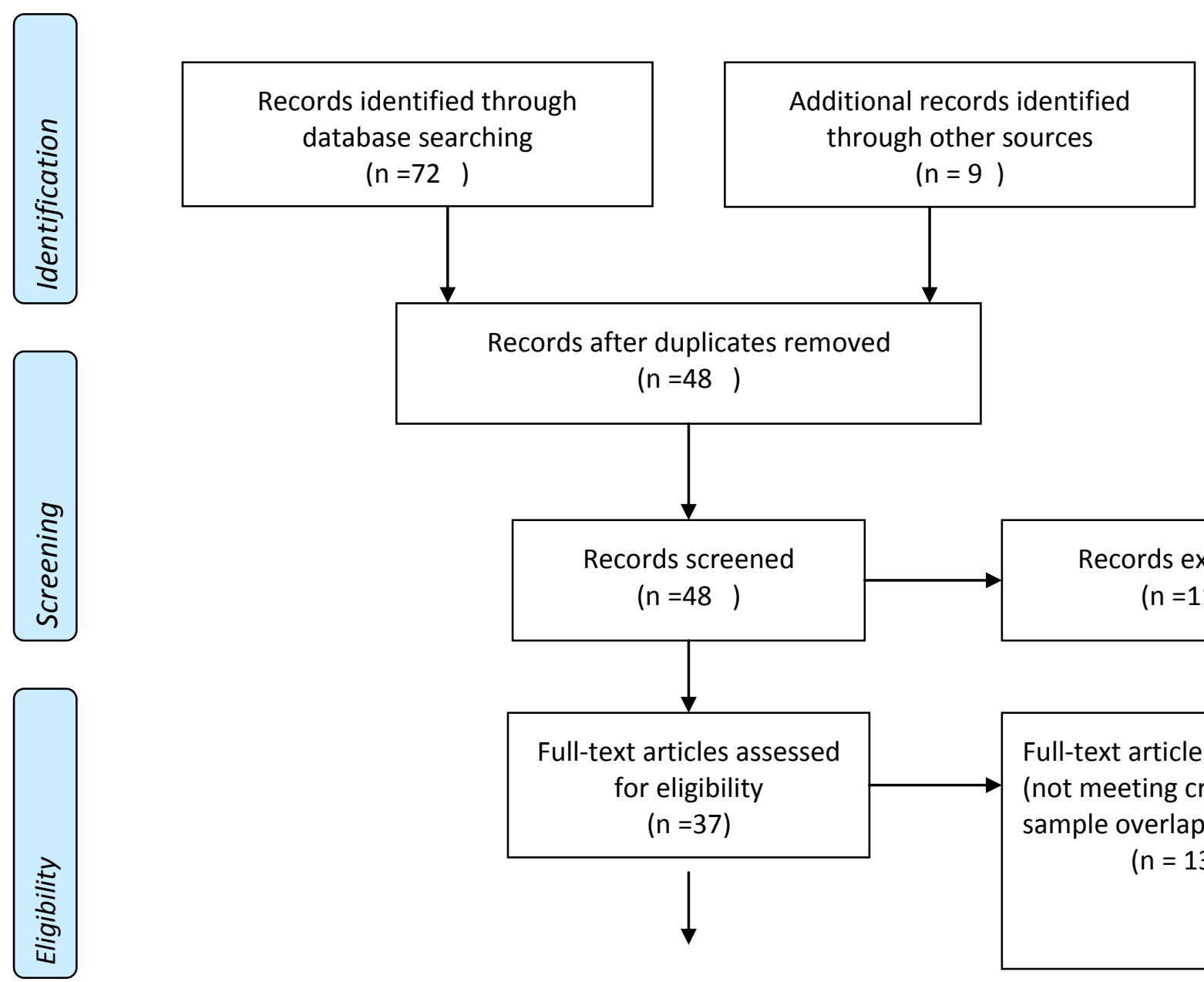

Full-text articles excluded (not meeting criteria or sample overlap)

$$
(n=13 \text { ) }
$$

Studies included in quantitative synthesis

(meta-analysis)

$$
(n=24)
$$




\begin{tabular}{lll} 
Study ID & Year & Cohen d/SE \\
Berneiser & 2014 & $0.27 / 0.19$ \\
Pinto & 2012 & $0.23 / 0.19$ \\
Prochnow & 2011 & $0.44 / 0.22$ \\
Henry & 2011 & $0.93 / 0.23$ \\
Philips & 2011 & $0.82 / 0.26$ \\
Lenne & 2014 & $0.94 / 0.27$ \\
Cecchetto & 2014 & $0.8 / 0.27$ \\
Henry & 2009 & $0.39 / 0.27$ \\
Jehna & 2010 & $0.15 / 0.31$ \\
Beatty & 1989 & $1.25 / 0.34$ \\
Jehna & 2011 & $0.01 / 0.37$ \\
Di Bitonto & 2011 & $0.21 / 0.4$ \\
Brandon_RR & 2015 & $-0.23 / 0.3$ \\
Brandon_SP & 2015 & $0.8 / 0.32$ \\
Parada_Fernandez & 2015 & $1.53 / 0.24$ \\
Radlak_CP & 2014 & $0.82 / 0.34$ \\
Radlak_RR & 2014 & $0.88 / 0.33$ \\
META_ANALYSIS: & & \\
\hline
\end{tabular}

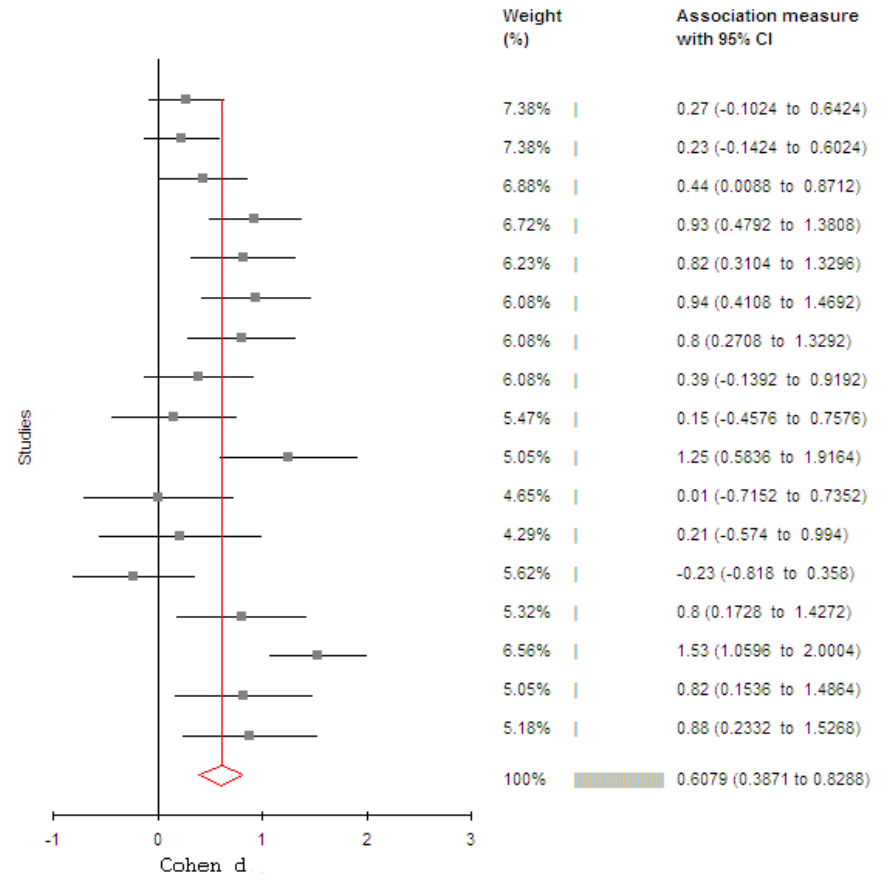




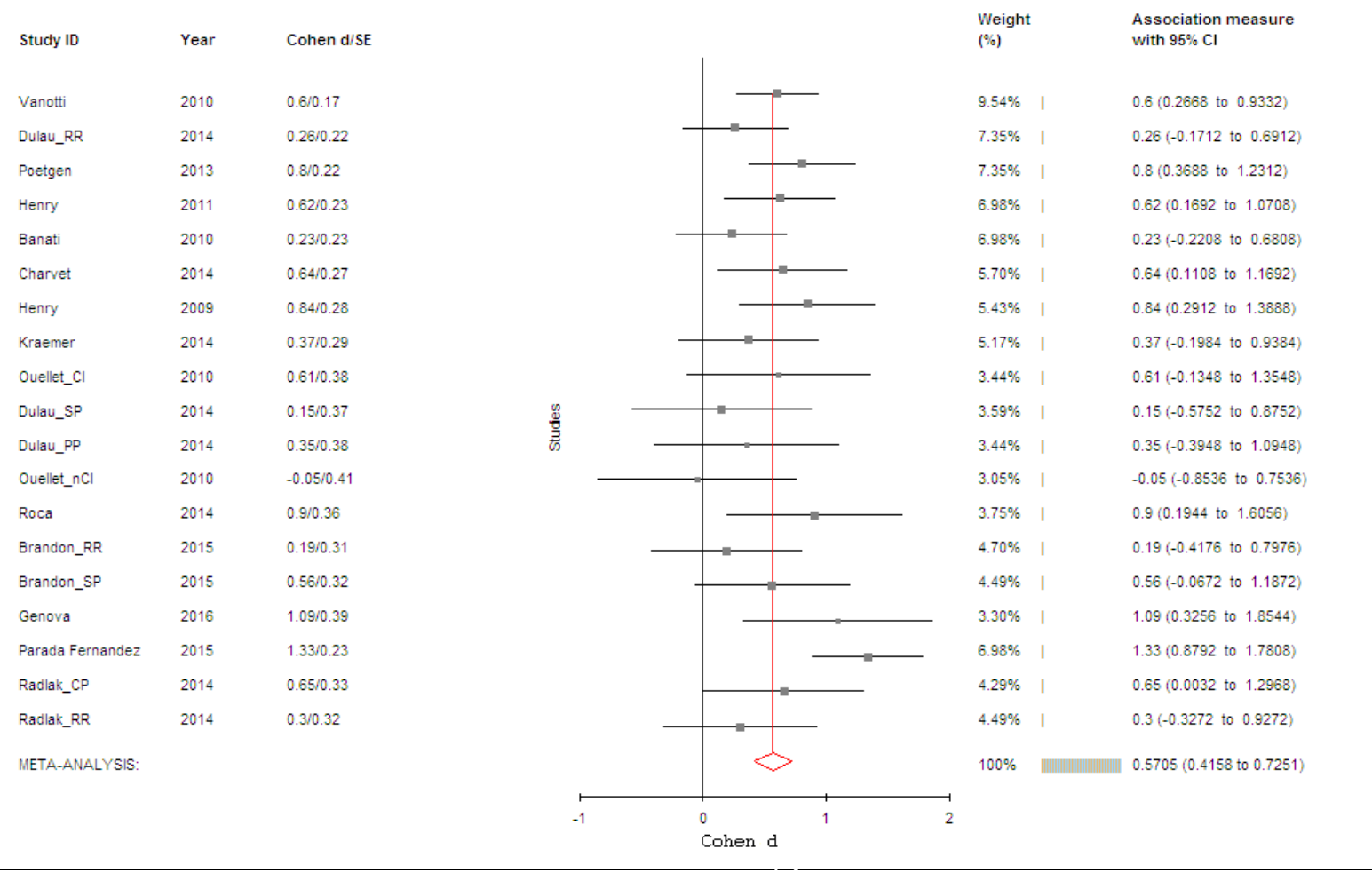


Table-1 Clinical and demographic characteristics of the studies included in the meta-analysis

\begin{tabular}{|c|c|c|c|c|c|c|c|}
\hline $\begin{array}{l}\text { First } \\
\text { author }\end{array}$ & \begin{tabular}{l|} 
Sampl \\
e
\end{tabular} & $\begin{array}{l}\text { Cognitive } \\
\text { tasks }\end{array}$ & \begin{tabular}{|l|} 
Social \\
cognitio \\
$\mathrm{n}$ task
\end{tabular} & Characteristics & MS symptoms & Medication & Outcome \\
\hline $\begin{array}{l}\text { Banati } \\
\text { et al } \\
2010\end{array}$ & $\begin{array}{l}40 \mathrm{MS} \\
35 \mathrm{HC}\end{array}$ & IQ & \begin{tabular}{|l} 
Faux pas \\
RMET
\end{tabular} & Age $=36.2$ & $\begin{array}{l}37 \mathrm{RR}, 3 \mathrm{SP} \\
\mathrm{EDSS}=2.3 \\
\text { All EDSS }<4.5\end{array}$ & No mention & $\begin{array}{l}\text { Nonverbal } \\
\text { ToM } \\
\text { impaired } \\
\text { Faux pas } \\
\text { impaired } \\
\text { only } \\
\text { in patients } \\
\text { with more } \\
\text { severe } \\
\text { disability }\end{array}$ \\
\hline $\begin{array}{l}\text { Beatty } \\
\text { et al } \\
1989\end{array}$ & $\begin{array}{l}21 \mathrm{MS} \\
19 \mathrm{HC}\end{array}$ & $\begin{array}{l}\text { BFRT } \\
\text { MMSE }\end{array}$ & \begin{tabular}{|l|} 
Face \\
emotion \\
(Ekman)
\end{tabular} & $\begin{array}{l}\text { Age }=52 \\
\text { Duration }=18.4 \\
\text { EDSS }=6.6\end{array}$ & $\begin{array}{l}\text { Chronic } \\
\text { progressive } \\
\text { EDSS }=6.6 \\
\text { BDI }=7.3\end{array}$ & & Impaired \\
\hline $\begin{array}{l}\text { Bernesie } \\
r \\
\text { et al } \\
2014\end{array}$ & $\begin{array}{l}61 \mathrm{MS} \\
53 \mathrm{HC}\end{array}$ & $\begin{array}{l}\text { PASAT } \\
\text { (only MS) }\end{array}$ & \begin{tabular}{|l} 
Face \\
emotion \\
(FAB)
\end{tabular} & $\begin{array}{l}\text { Age }=42.2 \\
\text { Duration }=6.1 \\
\text { BDI=9.2 }\end{array}$ & $\begin{array}{l}\mathrm{RR}=47, \mathrm{SP}=11 \\
\mathrm{PP}=3 \\
\mathrm{EDSS}=3.7\end{array}$ & No details & $\begin{array}{l}\text { MS impaired } \\
\text { More in SP } \\
\text { than RR }\end{array}$ \\
\hline $\begin{array}{l}\text { Brandon } \\
2015\end{array}$ & $31 \mathrm{HC}$ & $\begin{array}{l}\text { PASAT, } \\
\text { SDMT, } \\
\text { Verbal } \\
\text { memory, } \\
\text { Verbal } \\
\text { fluency, } \\
\text { TMT, } \\
\text { Stroop, } \\
\text { Digit } \\
\text { span, } \\
\text { BFRT }\end{array}$ & $\begin{array}{l}\text { Face } \\
\text { emotion } \\
\text { (ACS) } \\
\text { RMET }\end{array}$ & & & No details & \\
\hline$-\mathrm{RR}^{*}$ & $34 \mathrm{MS}$ & & & $\begin{array}{l}\text { Age }=46.1 \\
\text { Duration }=7.4\end{array}$ & All RR & & $\begin{array}{l}\text { No } \\
\text { difference }\end{array}$ \\
\hline -SP* & $32 \mathrm{MS}$ & & & $\begin{array}{l}\text { Age }=56.9 \\
\text { Duration }=20.2\end{array}$ & All SP & & MS impaired \\
\hline $\begin{array}{l}\text { Cecchett } \\
\text { o } \\
\text { et al } \\
2014\end{array}$ & $\begin{array}{l}30 \mathrm{MS} \\
30 \mathrm{HC}\end{array}$ & $\begin{array}{l}\text { IQ } \\
\text { PASAT, } \\
\text { SDMT, } \\
\text { other } \\
\text { tasks } \\
\text { (only } \\
\text { patients) }\end{array}$ & $\begin{array}{l}\text { Face } \\
\text { emotion } \\
\text { (Nim } \\
\text { Set) }\end{array}$ & & $\begin{array}{l}\text { All RR } \\
\text { EDSS }<4.5 \\
\text { Mean=2 }\end{array}$ & No details & MS impaired \\
\hline $\begin{array}{l}\text { Charvet } \\
\text { et al } \\
2014\end{array}$ & $\begin{array}{l}28 \mathrm{MS} \\
32 \mathrm{HC}\end{array}$ & $\begin{array}{l}\text { IQ, } \\
\text { SDMT }\end{array}$ & \begin{tabular}{|l} 
RMET \\
Faux pas \\
False \\
belief
\end{tabular} & $\begin{array}{l}\mathrm{Age}=16.3 \\
\text { Duration=2.5(2. } \\
\text { 5) }\end{array}$ & $\begin{array}{l}\text { Pediatric onset } \\
\text { EDSS }<4.5 \\
\text { Median } \\
\text { EDSS }=1\end{array}$ & $\begin{array}{l}\text { No details } \\
\text { Steroid free for } \\
30 \\
\text { days or more }\end{array}$ & $\begin{array}{l}\text { Impaired } \\
\text { Correlated } \\
\text { with SDMT }\end{array}$ \\
\hline $\begin{array}{l}\text { Di } \\
\text { Bitonto } \\
\text { et al } \\
2011\end{array}$ & $\begin{array}{l}13 \mathrm{MS} \\
13 \mathrm{HC}\end{array}$ & BFRT & $\begin{array}{l}\text { Face } \\
\text { emotion } \\
\text { (Ekman) }\end{array}$ & Age $=42$ & $\begin{array}{l}\text { All RR } \\
\text { EDSS=2.8(1.6) }\end{array}$ & $\begin{array}{l}\text { All on immune } \\
\text { modulatory } \\
\text { treatment }\end{array}$ & \begin{tabular}{|l|} 
No \\
difference
\end{tabular} \\
\hline $\begin{array}{l}\text { Dulau } \\
2014\end{array}$ & & $\begin{array}{l}\text { WCST, } \\
\text { letter } \\
\text { fluency, } \\
\text { Stroop, } \\
\text { PASAT }\end{array}$ & \begin{tabular}{|l} 
RMET \\
Faux pas \\
Intention
\end{tabular} & & & No details & \begin{tabular}{|l} 
Social \\
cognitive \\
impairment \\
Pronounced \\
in \\
cognitively \\
impaired \\
\end{tabular} \\
\hline
\end{tabular}




\begin{tabular}{|c|c|c|c|c|c|c|c|}
\hline & & & & & & & patients \\
\hline$-\mathrm{RR}$ & $\begin{array}{l}30 \mathrm{MS} \\
80 \mathrm{HC}\end{array}$ & & & $\begin{array}{l}\text { Age }=41 \\
\text { Duration }=11.5\end{array}$ & $\begin{array}{l}\mathrm{EDSS}=2 \\
(0-4.5)\end{array}$ & & $\begin{array}{l}\text { RMET } \\
\text { impaired }\end{array}$ \\
\hline$-\mathrm{SP}^{*}$ & $\begin{array}{l}15 \mathrm{MS} \\
29 \mathrm{HC}\end{array}$ & & & $\begin{array}{l}\text { Age }=51 \\
\text { Duration }=18.8\end{array}$ & $\mathrm{EDSS}=4$ & & $\begin{array}{l}\text { No } \\
\text { significant } \\
\text { difference } \\
\text { from RR }\end{array}$ \\
\hline -PP* & $\begin{array}{l}15 \mathrm{MS} \\
29 \mathrm{HC}\end{array}$ & & & $\begin{array}{l}\text { Age }=54.8 \\
\text { Duration }=10\end{array}$ & $\mathrm{EDSS}=4$ & & $\begin{array}{l}\text { No } \\
\text { significant } \\
\text { difference } \\
\text { from RR }\end{array}$ \\
\hline $\begin{array}{l}\text { Genova } \\
\text { et al } \\
2016\end{array}$ & $\begin{array}{l}15 \mathrm{MS} \\
15 \mathrm{HC}\end{array}$ & $\begin{array}{l}\text { SDMT, } \\
\text { PASAT, } \\
\text { Digit } \\
\text { span, } \\
\text { verbal } \\
\text { learning }\end{array}$ & $\begin{array}{l}\text { TASIT } \\
\text { ToM }\end{array}$ & $\begin{array}{l}\text { Age }=49.5 \\
\text { Duration }=18\end{array}$ & $\begin{array}{l}10 \mathrm{RR}, 5 \\
\text { chronic } \\
\text { progressive }\end{array}$ & No details & Impaired \\
\hline $\begin{array}{l}\text { Henry et } \\
\text { al } \\
2009\end{array}$ & $\begin{array}{l}27 \mathrm{MS} \\
30 \mathrm{HC}\end{array}$ & $\begin{array}{l}\text { Semantic } \\
\& \text { letter } \\
\text { Fluency, } \\
\text { SDMT } \\
\text { Vocabular } \\
\text { y } \\
\text { Verbal } \\
\text { learning }\end{array}$ & $\begin{array}{l}\text { Face } \\
\text { emotion } \\
\text { (Ekman) } \\
\text { RMET }\end{array}$ & $\begin{array}{l}\text { Age }=47 \\
\text { Duration }=7(6)\end{array}$ & $\begin{array}{l}\text { Disease } \\
\text { steps }=1.9(2.0)\end{array}$ & No details & $\begin{array}{l}\text { ToM, anger, } \\
\text { fear } \\
\text { impaired } \\
\text { Correlated } \\
\text { with fluency }\end{array}$ \\
\hline $\begin{array}{l}\text { Henry et } \\
\text { al } \\
2011\end{array}$ & $\begin{array}{l}64 \mathrm{MS} \\
30 \mathrm{HC}\end{array}$ & $\begin{array}{l}\text { IQ } \\
\text { Brixton }\end{array}$ & $\begin{array}{l}\text { False } \\
\text { belief } \\
\text { Faux pas } \\
\text { Face } \\
\text { emotion } \\
\text { (Ekman) }\end{array}$ & $\begin{array}{l}\text { Age }=42.4 \\
\text { Duration }=9.1\end{array}$ & $\begin{array}{l}\text { ALL RR } \\
\text { EDSS }<5.5 \\
\text { EDSS }=2.3\end{array}$ & No details & $\begin{array}{l}\text { Impaired in } \\
\text { social } \\
\text { cognition }\end{array}$ \\
\hline $\begin{array}{l}\text { Jehna et } \\
\text { al } \\
2010\end{array}$ & $\begin{array}{l}20 \mathrm{MS} \\
23 \mathrm{HC}\end{array}$ & & $\begin{array}{l}\text { Facial } \\
\text { emotion }\end{array}$ & $\begin{array}{l}\text { Age }=36.4 \\
\text { Duration }=7.3\end{array}$ & $\begin{array}{l}12 \text { Clinicaly } \\
\text { isolated } \\
7 \mathrm{RR}, 1 \mathrm{SP} \\
\mathrm{EDSS}=1.7(0.9)\end{array}$ & No details & $\begin{array}{l}\text { No } \\
\text { difference in } \\
\text { accuracy } \\
\text { Reaction to } \\
\text { emotional } \\
\text { stimuli } \\
\text { slower in MS }\end{array}$ \\
\hline $\begin{array}{l}\text { Jehna et } \\
\text { al } \\
2011\end{array}$ & $\begin{array}{l}15 \mathrm{MS} \\
15 \mathrm{HC}\end{array}$ & $\begin{array}{l}\text { PASAT, } \\
\text { WCST, } \\
\text { SDMT, } \\
\text { verbal } \\
\text { fluency, } \\
\text { memory }\end{array}$ & $\begin{array}{l}\text { Face } \\
\text { emotion } \\
(\mathrm{BERT})\end{array}$ & $\begin{array}{l}\text { Age }=29.5 \\
\text { Duration }=3.3\end{array}$ & $\begin{array}{l}\text { All RR } \\
\text { EDSS }=1.7 \\
\text { EDSS }<4\end{array}$ & $\begin{array}{l}14 / 16 \text { immune } \\
\text { modulatory } \\
\text { treatment }\end{array}$ & $\begin{array}{l}\text { No } \\
\text { impairment } \\
\text { in } \\
\text { emotion } \\
\text { recognition }\end{array}$ \\
\hline $\begin{array}{l}\text { Kraemer } \\
\text { et al } \\
2014\end{array}$ & $\begin{array}{l}25 \mathrm{MS} \\
25 \mathrm{HC}\end{array}$ & $\begin{array}{l}\text { Stroop, } \\
\text { TMT, } \\
\text { Number- } \\
\text { letter }\end{array}$ & MASC & $\begin{array}{l}\text { Age }=30.9 \\
\text { Duration }=1.2 \\
\text { All<2 years }\end{array}$ & $\begin{array}{l}\text { All RR } \\
\text { EDSS=0.96 } \\
\text { EDSS }<2.5\end{array}$ & $\begin{array}{l}22 / 25 \text { on immune } \\
\text { modulatory } \\
\text { treatment } \\
\mathrm{BDI}=9.2\end{array}$ & $\begin{array}{l}\text { ToM } \\
\text { impaired } \\
\text { ToM } \\
\text { correlated } \\
\text { with } \\
\text { Stroop }\end{array}$ \\
\hline $\begin{array}{l}\text { Lenne et } \\
\text { al } \\
2014\end{array}$ & $\begin{array}{l}55 \mathrm{MS} \\
21 \mathrm{HC}\end{array}$ & $\begin{array}{l}\text { PASAT, } \\
\text { Digit } \\
\text { span, } \\
\text { Verbal } \\
\text { learning, } \\
\text { Digit } \\
\text { symbol, } \\
\text { Verbal } \\
\text { Fluency, } \\
\text { Go NoGo }\end{array}$ & $\begin{array}{l}\text { Face } \\
\text { emotion } \\
(\text { Ekman) }\end{array}$ & $\begin{array}{l}\text { Age }=39.8 \\
\text { Duration }=7.5(6)\end{array}$ & $\begin{array}{l}\text { All RR } \\
\text { EDSS=2(media } \\
\text { n) }\end{array}$ & Not mentioned & $\begin{array}{l}\text { Impaired } \\
\text { Especially } \\
\text { anger, } \\
\text { sadness } \\
\text { and fear }\end{array}$ \\
\hline
\end{tabular}




\begin{tabular}{|c|c|c|c|c|c|c|c|}
\hline $\begin{array}{l}\text { Ouellet } \\
2010 \\
(43)\end{array}$ & $\begin{array}{|ll|}41 \mathrm{MS} \\
20 \mathrm{HC}\end{array}$ & $\begin{array}{l}26 \\
\text { Cognitivel } \\
\text { y } \\
\text { impaired } \\
15 \text { not- } \\
\text { impaired }\end{array}$ & $\begin{array}{l}\text { Faux pas } \\
\text { Happe } \\
\text { stories } \\
\text { C I }\end{array}$ & & $\begin{array}{l}22 \mathrm{RR}, 13 \mathrm{SP}, 5 \\
\text { SP }\end{array}$ & Not mentioned & $\begin{array}{l}\text { ToM } \\
\text { impaired } \\
\text { More in } \\
\text { cognitively } \\
\text { impaired } \\
\text { group }\end{array}$ \\
\hline $\begin{array}{l}\text { Parada- } \\
\text { Fernande } \\
\text { z } 2015\end{array}$ & $\begin{array}{l}45 \mathrm{MS} \\
40 \mathrm{HC}\end{array}$ & & $\begin{array}{l}\text { Face } \\
\text { emotion } \\
\text { (FEEL) } \\
\text { RMET }\end{array}$ & Age $=49.4$ & $\begin{array}{l}24 \mathrm{RR}, 21 \\
\text { chronic } \\
\text { progressive }\end{array}$ & No detail & Impaired \\
\hline $\begin{array}{l}\text { Philips } \\
\text { et al } \\
2011\end{array}$ & $\begin{array}{l}32 \mathrm{MS} \\
33 \mathrm{HC}\end{array}$ & $\begin{array}{l}\text { BFRT } \\
\text { Verbal } \\
\text { fluency, } \\
\text { Go NoGo, } \\
\text { Verbal } \\
\text { memory } \\
\end{array}$ & $\begin{array}{l}\text { Face } \\
\text { emotion } \\
\text { (Ekman } \\
\text { Morphe } \\
\text { d) }\end{array}$ & $\begin{array}{l}\text { Age }=44.0 \\
\text { Duration=7.9(5. } \\
5)\end{array}$ & $\begin{array}{l}27 \mathrm{RR}, 2 \mathrm{SP}, 3 \\
\mathrm{PP} \\
\text { Disease steps= } \\
2.2(1.7)\end{array}$ & $\begin{array}{l}21 / 27 \mathrm{RR} \text { on } \\
\text { disease } \\
\text { modifying } \\
\text { treatment } \\
\text { (mostly on } \\
\text { interferon) }\end{array}$ & Impaired \\
\hline $\begin{array}{l}\text { Pinto et } \\
\text { al } \\
2012\end{array}$ & \begin{tabular}{|l}
$56 \mathrm{MS}$ \\
$56 \mathrm{HC}$
\end{tabular} & $\begin{array}{l}\text { BFRT } \\
\text { matched } \\
\text { MS only: } \\
\text { Digit } \\
\text { span, } \\
\text { WCST, } \\
\text { Verbal } \\
\text { learning, } \\
\text { fluency }\end{array}$ & $\begin{array}{l}\text { Face } \\
\text { emotion } \\
\text { (Nim } \\
\text { Set) }\end{array}$ & $\begin{array}{l}\text { Age }=38.9 \\
\text { Duration }=9(6.2)\end{array}$ & $\begin{array}{l}48 \mathrm{RR}, 3 \mathrm{SP}, 5 \\
\mathrm{PP} \\
\mathrm{EDDS}=2.5(2.0) \\
\mathrm{HDRS}=4.5\end{array}$ & Not mentioned & $\begin{array}{l}\text { No } \\
\text { difference } \\
\text { Correlated } \\
\text { with } \\
\text { neurocogniti } \\
\text { on }\end{array}$ \\
\hline $\begin{array}{l}\text { Pottgen } \\
\text { et al } \\
2013\end{array}$ & $\begin{array}{l}45 \mathrm{MS} \\
45 \mathrm{HC}\end{array}$ & $\begin{array}{l}\text { MS only: } \\
\text { SDMT, } \\
\text { verbal } \\
\text { memory, } \\
\text { Nonverbal } \\
\text { logical } \\
\text { reasoning }\end{array}$ & MASC & $\begin{array}{l}\text { Age }=42.4 \\
\text { Duration=8.5(6. } \\
1)\end{array}$ & $\begin{array}{l}31 \mathrm{RR}, 8 \mathrm{SP}, \\
6 \mathrm{PP} \\
\mathrm{EDSS}=3.5\end{array}$ & Not mentioned & $\begin{array}{l}\text { MS impaired } \\
\text { in ToM } \\
\text { Remains to } \\
\text { be impaired } \\
\text { After } \\
\text { exclusion of } \\
\text { subjects } \\
\text { With severe } \\
\text { cognitive } \\
\text { deficit, } \\
\text { clinical } \\
\text { depression or } \\
\text { high } \\
\text { EDSS (>3.5) }\end{array}$ \\
\hline $\begin{array}{l}\text { Prochno } \\
\text { w } \\
\text { et al } \\
2011\end{array}$ & $\begin{array}{l}35 \mathrm{MS} \\
61 \mathrm{HC}\end{array}$ & $\begin{array}{l}\text { All BFRT } \\
\text { and } \\
\text { neutral } \\
\text { emotion } \\
\text { recognitio } \\
\text { n normal }\end{array}$ & $\begin{array}{l}\text { Face } \\
\text { emotion } \\
\text { (Ekman } \\
\text { and } \\
\text { PCFAE) }\end{array}$ & $\begin{array}{l}\text { Age=48.1 } \\
\text { Duration=9.2(8. } \\
4)\end{array}$ & $\begin{array}{l}\text { EDSS-median } \\
6 \\
\text { BDI=11.4 } \\
29 \mathrm{SP}, 5 \mathrm{RR}, 1 \\
\text { PP }\end{array}$ & $\begin{array}{l}\text { All- } \\
\text { immunosuppresa } \\
\text { nts } \\
\text { Mitoxantrone } 80 \\
\%\end{array}$ & $\begin{array}{l}\text { Impaired in } \\
\text { fear, anger, } \\
\text { Surprise, sad } \\
\text { faces } \\
\text { Disgust } \\
\text { impaired in } \\
\text { patients } \\
\text { with higher } \\
\text { EDSS }\end{array}$ \\
\hline $\begin{array}{l}\text { Radlak } \\
2014\end{array}$ & $31 \mathrm{HC}$ & $\begin{array}{l}\text { Verbal } \\
\text { fluency, } \\
\text { SDMT }\end{array}$ & $\begin{array}{l}\text { Face } \\
\text { emotion } \\
\text { (Ekman) } \\
\text { TASIT } \\
\text { ToM }\end{array}$ & & & & \\
\hline$-\mathrm{CP}^{*}$ & $26 \mathrm{MS}$ & & & $\begin{array}{l}\text { Age }=55.7 \\
\text { Duration }=14.1\end{array}$ & $\begin{array}{l}23 \mathrm{SP}, 3 \mathrm{PP} \\
\mathrm{PDDS}=5.4 \\
(1.7) \\
0-8 \\
\mathrm{HDRS}=7\end{array}$ & $\begin{array}{l}\text { None on disease } \\
\text { modifying } \\
\text { treatment }\end{array}$ & $\begin{array}{l}\text { Impaired in } \\
\text { ToM and } \\
\text { emotion } \\
\text { recognition }\end{array}$ \\
\hline
\end{tabular}




\begin{tabular}{|l|l|l|l|l|l|l|l|}
\hline -RR* & $30 \mathrm{MS}$ & & $\begin{array}{l}\text { Age=44.7 } \\
\text { Duration=10.1 }\end{array}$ & $\begin{array}{l}\text { PDSS=1.8 (1.7) } \\
0-5 \\
\text { HDRS=4.2 }\end{array}$ & $\begin{array}{l}\text { 16/31 on disease } \\
\text { modifying } \\
\text { treatment }\end{array}$ & $\begin{array}{l}\text { Impaired in } \\
\text { emotion } \\
\text { recognition }\end{array}$ \\
\hline $\begin{array}{l}\text { Roca et } \\
\text { al } \\
2014\end{array}$ & $\begin{array}{l}18 \mathrm{MS} \\
16 \mathrm{HC}\end{array}$ & $\begin{array}{l}\text { PASAT, } \\
\text { FAB, } \\
\text { Digit } \\
\text { Span, } \\
\text { WCST, } \\
\text { TMT, } \\
\text { Verbal } \\
\text { fluency }\end{array}$ & Faux pas & $\begin{array}{l}\text { Age=40.7 } \\
\text { Duration=5.1 } \\
(3.8)\end{array}$ & $\begin{array}{l}\text { All RR } \\
\text { Mild (EDSS 0- } \\
3) \\
\text { Mean=0.6 }\end{array}$ & $\begin{array}{l}\text { All on disease } \\
\text { modifying } \\
\text { treatment }\end{array}$ & $\begin{array}{l}\text { Impaired } \\
\text { in cognitive } \\
\text { score only } \\
\text { Correlated } \\
\text { with } \\
\text { neurocogniti } \\
\text { on }\end{array}$ \\
\hline $\begin{array}{l}\text { Vanotti } \\
\text { et al } \\
2012\end{array}$ & $\begin{array}{l}121 \\
\text { MS } \\
53 \mathrm{HC}\end{array}$ & PASAT & RMET & $\begin{array}{l}\text { Age=36.4 } \\
\text { Duration=3.5(0. } \\
\text { 3) }\end{array}$ & $\begin{array}{l}\text { All RR } \\
\text { EDSS=2.5(1.5) }\end{array}$ & & \\
\hline
\end{tabular}

$\mathrm{MS}=$ Multiple sclerosis, $\mathrm{RR}=$ Relapsing-remitting, $\mathrm{PP}=$ Primary progressive, $\mathrm{SP}=\mathrm{Secondary}$ progressive, $\mathrm{EDSS}=$ Expanded Disability Status Scale,

BDI= Beck Depression inventory, PASAT $=$ Paced Auditory Serial Addition Test $\quad$ SDMT $=$ Symbol Digit Modalities Test, RMET=Reading the mind from the eyes test, BFRT=Benton facial recognition test,

$\mathrm{FAB}=$ Frontal assessment battery, WCST $=$ Wisconsin cart sorting test, $\mathrm{TMT}=$ Trail making test

MASC $=$ Movie for the Assessment of Social Cognition, FAB=Florida Affect Battery, ACS=Advanced Clinical Solutions social perception subtest,

BERT=Behavioral Emotion Recognition Test, PCFAE $=$ Test of Perceptual Competence of Facial Affect Recognition

PDDS=Patient determined disease steps, ${ }^{*}=$ Sharing control group 
Table-2 mean weighted effect sizes for differences between patients with MS and healthy controls on social cognition tasks

\begin{tabular}{|c|c|c|c|c|c|c|c|c|c|c|c|c|c|}
\hline Test & $\begin{array}{l}\text { Study } \\
\mathrm{N}\end{array}$ & MS & $\mathrm{HC}$ & $\mathrm{d}$ & $95 \% \mathrm{CI}$ & $\mathrm{Z}$ & $\mathrm{P}$ & $\mathrm{Q}$ & $\mathrm{Q}(\mathrm{p})$ & $\tau^{2}$ & $\begin{array}{l}\text { Bias } \\
\text { (p) }\end{array}$ & $\begin{array}{l}\mathrm{I}^{2} \\
(\%)\end{array}$ & $\begin{array}{l}\text { Estimated Cohen } \mathrm{d}(\mathrm{CI}) \\
\text { Trim and fill }\end{array}$ \\
\hline $\begin{array}{l}\text { Social } \\
\text { cognition }\end{array}$ & 29 & 989 & 836 & 0.56 & $0.42-0.69$ & 8.2 & $<0.001$ & 48.4 & 0.001 & 0.05 & 0.93 & 42 & No change \\
\hline ToM & 19 & 651 & 512 & 0.57 & $0.42-0.73$ & 7.2 & $<0.001$ & 26.5 & 0.09 & 0.04 & 0.48 & 32 & No change \\
\hline $\begin{array}{l}\text {-ToM- } \\
\text { PT }\end{array}$ & 14 & 392 & 358 & 0.39 & $0.17-0.61$ & 3.5 & $<0.001$ & 25.7 & 0.02 & 0.08 & 0.21 & 49 & No change \\
\hline $\begin{array}{l}\text {-Faux } \\
\text { pas }\end{array}$ & 9 & 251 & 242 & 0.25 & $-0.04-0.55$ & 1.7 & 0.09 & 17.9 & 0.02 & 0.11 & 0.35 & 55 & No change \\
\hline -RMET & 10 & 387 & 330 & 0.67 & $0.47-0.88$ & 6.4 & $<0.001$ & 14.1 & 0.12 & 0.04 & 0.28 & 36 & No change \\
\hline $\begin{array}{l}\text { Facial } \\
\text { emotion }\end{array}$ & 17 & 596 & 486 & 0.61 & $0.39-0.83$ & 5.4 & $<0.001$ & 46.3 & $<0.001$ & 0.14 & 0.75 & 65 & No change \\
\hline -Anger & 10 & 366 & 297 & 0.56 & $0.32-0.80$ & 4.6 & $<0.001$ & 18.5 & 0.03 & 0.07 & 0.84 & 51 & No change \\
\hline -Fear & 9 & 310 & 241 & 0.54 & $0.34-0.73$ & 5.6 & $<0.001$ & 9.0 & 0.35 & 0.01 & 0.10 & 11 & No change \\
\hline -Sad & 9 & 351 & 282 & 0.32 & $0.16-0.49$ & 3.8 & 0.001 & 6.8 & 0.45 & 0 & 0.81 & 0 & No change \\
\hline -Happy & 9 & 351 & 282 & 0.22 & $0.04-0.39$ & 2.4 & 0.01 & 6.0 & 0.31 & 0.01 & 0.91 & 17 & No change \\
\hline -Disgust & 9 & 311 & 276 & 0.25 & $0.01-0.50$ & 2.1 & 0.04 & 15.6 & 0.05 & 0.06 & 0.86 & 48 & No change \\
\hline - & 8 & 296 & 261 & 0.32 & $0.12-0.52$ & 3.2 & 0.002 & 8.7 & 0.27 & 0.02 & 0.47 & 20 & No change \\
\hline
\end{tabular}

MS=Multiple Sclerosis HC=Healthy controls, $d=$ Cohen's d, ToM=Theory of mind, $\mathrm{CI}=$ Confidence interval 
Table-3 Subgroup analyses for social cognition deficis in MS

\begin{tabular}{|c|c|c|c|c|c|c|c|c|c|c|}
\hline Test & Study N & $\mathrm{d}$ & $95 \% \mathrm{CI}$ & $\mathrm{Z}$ & $\mathrm{P}$ & $\mathrm{Q}$ & $\mathrm{Q}(\mathrm{p})$ & $\tau^{2}$ & $\mathrm{I}^{2}(\%)$ & $\mathrm{Q}_{\text {bet }}$ \\
\hline $\begin{array}{l}\text { Social } \\
\text { cognition }\end{array}$ & 29 & 0.56 & $0.42-0.69$ & 8.2 & $<0.001$ & 48.4 & 0.001 & 0.05 & 42 & \\
\hline Age & & & & & & & & & & 1.2 \\
\hline -Matched & 21 & 0.59 & $0.43-0.75$ & 7.4 & $<0.001$ & 38.3 & 0.008 & 0.06 & 48 & \\
\hline -Not matched & 8 & 0.44 & $0.20-0.69$ & 3.5 & $<0.001$ & 8.9 & 0.26 & 0.03 & 21 & \\
\hline Education & & & & & & & & & & 0.05 \\
\hline -Matched & 19 & 0.55 & $0.42-0.69$ & 8.2 & $<0.001$ & 20.7 & 0.29 & 0.01 & 13 & \\
\hline -Not matched & 10 & 0.56 & $0.26-0.86$ & 3.6 & $<0.001$ & 27.7 & 0.001 & 0.15 & 68 & \\
\hline $\begin{array}{l}\text { Depressive } \\
\text { symptoms }\end{array}$ & & & & & & & & & & 1.6 \\
\hline -No difference & 7 & 0.45 & $0.27-0.64$ & 4.8 & $<0.001$ & 6.5 & 0.37 & 0.01 & 8 & \\
\hline -More in MS & 15 & 0.59 & $0.35-0.82$ & 4.9 & $<0.001$ & 33.8 & 0.002 & 0.12 & 58 & \\
\hline Cognition & & & & & & & & & & $16.4 * *$ \\
\hline -Impaired & 14 & 0.82 & $0.65-0.99$ & 9.3 & $<0.001$ & 15.2 & 0.29 & 0.02 & 15 & \\
\hline -Not impaired & 10 & 0.36 & $0.17-0.54$ & 3.8 & $<0.001$ & 11.2 & 0.26 & 0.02 & 20 & \\
\hline $\begin{array}{l}\text { Mild/moderate } \\
\text { only } \\
\text { (disability) }\end{array}$ & & & & & & & & & & 1.3 \\
\hline -Yes & 10 & 0.43 & $0.25-0.61$ & 4.7 & $<0.001$ & 11.1 & 0.27 & 0.02 & 19 & \\
\hline$-\mathrm{No}$ & 12 & 0.55 & $0.37-0.73$ & 6.0 & $<0.001$ & 14.5 & 0.21 & 0.02 & 24 & \\
\hline
\end{tabular}

MS=Multiple Sclerosis HC=Healthy controls, $d=$ Cohen's d, ToM=Theory of mind, ** $0.01>p$ 
Social cognition in multiple sclerosis: a meta-analysis

Emre Bora $^{1}$, Serkan Özakbaş ${ }^{2}$, Dennis Velakoulis ${ }^{1}$, Mark Walterfang ${ }^{1,3}$

Supplement-1 Forest plots of meta-analyses of social cognition measures in MS

Figure S1.1 Forest plot of meta-analysis of social cognition in MS compared to healthy controls

\begin{tabular}{|c|c|c|}
\hline Study ID & Year & Cohen $\mathrm{d} / \mathrm{SE}$ \\
\hline Banati & 2010 & $0.23 / 0.23$ \\
\hline Beatty & 1989 & $1.25 / 0.34$ \\
\hline Berneiser & 2014 & $0.27 / 0.19$ \\
\hline Cecchetto & 2014 & 0.810 .27 \\
\hline Charvet & 2014 & $0.64 / 0.27$ \\
\hline Dulau_RR & 2014 & $0.26 / 0.22$ \\
\hline Dulau_SP & 2014 & $0.15 / 0.37$ \\
\hline Dulau_pP & 2014 & $0.35 / 0.38$ \\
\hline Henry & 2009 & $0.62 / 0.28$ \\
\hline Henry & 2011 & $0.78 / 0.23$ \\
\hline Kraemer & 2014 & $0.37 / 0.29$ \\
\hline Lenne & 2014 & $0.94 / 0.27$ \\
\hline Ouellet_Cl & 2010 & $0.61 / 0.38$ \\
\hline Ouellet_nCl & 2010 & $-0.05 / 0.41$ \\
\hline Philips & 2011 & $0.82 / 0.26$ \\
\hline Pinto & 2012 & $0.23 / 0.19$ \\
\hline Poetgen & 2013 & $0.8 / 0.22$ \\
\hline Prochnow & 2011 & $0.44 / 0.22$ \\
\hline Roca & 2014 & $0.9 / 0.36$ \\
\hline Jehna & 2010 & $0.15 / 0.31$ \\
\hline Jenna & 2011 & $0.01 / 0.37$ \\
\hline Vanotti & 2012 & $0.6 / 0.17$ \\
\hline Di Bitonto & 2011 & $0.21 / 0.4$ \\
\hline Brandon_RR & 2015 & $-0.02 / 0.31$ \\
\hline Brandon_SP & 2015 & $0.68 / 0.32$ \\
\hline Genova & 2016 & $1.09 / 0.39$ \\
\hline Parada Fernandez & 2015 & $1.43 / 0.24$ \\
\hline Radlak_CP & 2014 & $0.74 / 0.33$ \\
\hline Radlak_RR & 2014 & $0.59 / 0.32$ \\
\hline
\end{tabular}

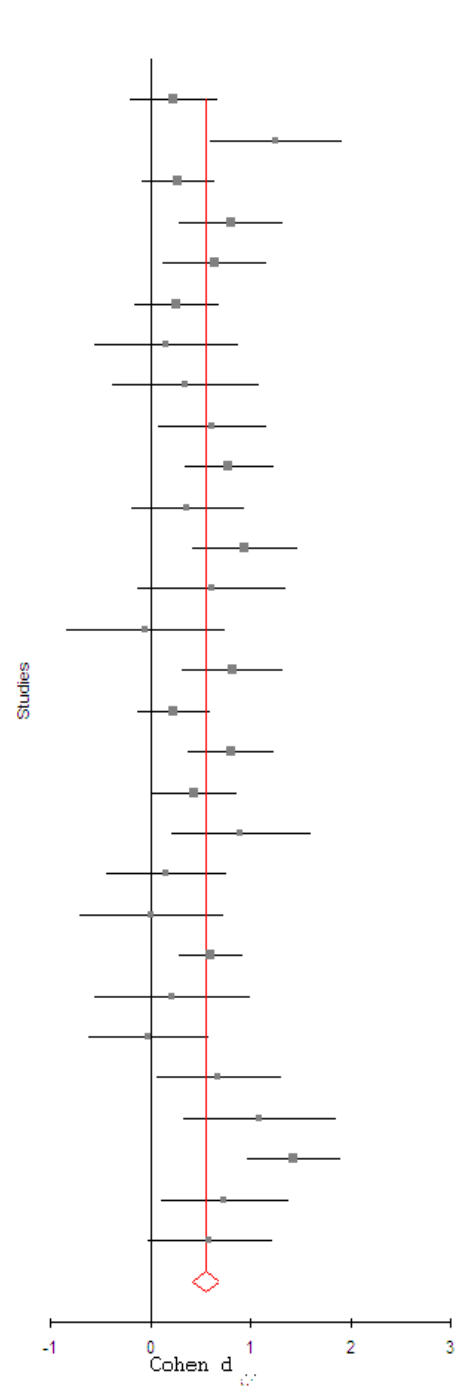

\begin{tabular}{|c|c|c|}
\hline $\begin{array}{l}\text { Weight } \\
(\%)\end{array}$ & & $\begin{array}{l}\text { Association measure } \\
\text { with } 95 \% \mathrm{Cl}\end{array}$ \\
\hline $4.33 \%$ & I & $0.23(-0.2208$ to 0.6808$)$ \\
\hline $2.73 \%$ & I & $1.25(0.5836$ to 1.9164$)$ \\
\hline $5.15 \%$ & I & $0.27(-0.1024$ to 0.6424$)$ \\
\hline $3.65 \%$ & 1 & $0.8(0.2708$ to 1.3292$)$ \\
\hline $3.65 \%$ & I & $0.64(0.1108$ to 1.1692$)$ \\
\hline $4.52 \%$ & I & $0.26(-0.1712$ to 0.6912$)$ \\
\hline $2.42 \%$ & I & $0.15(-0.5752$ to 0.8752$)$ \\
\hline $2.33 \%$ & I & $0.35(-0.3948$ to 1.0948$)$ \\
\hline $3.49 \%$ & I & $0.62(0.0712$ to 1.1688$)$ \\
\hline $4.33 \%$ & 1 & $0.78(0.3292$ to 1.2308$)$ \\
\hline $3.35 \%$ & 1 & $0.37(-0.1984$ to 0.9384$)$ \\
\hline $3.65 \%$ & I & $0.94(0.4108$ to 1.4692$)$ \\
\hline $2.33 \%$ & I & $0.61(-0.1348$ to 1.3548$)$ \\
\hline $2.08 \%$ & 1 & $-0.05(-0.8536$ to 0.7536$)$ \\
\hline $3.81 \%$ & I & $0.82(0.3104$ to 1.3296$)$ \\
\hline $5.15 \%$ & I & $0.23(-0.1424$ to 0.6024$)$ \\
\hline $4.52 \%$ & 1 & $0.8(0.3688$ to 1.2312$)$ \\
\hline $4.52 \%$ & 1 & $0.44(0.0088$ to 0.8712$)$ \\
\hline $2.52 \%$ & I & $0.9(0.1944$ to 1.6056$)$ \\
\hline $3.08 \%$ & I & $0.15(-0.4576$ to 0.7576$)$ \\
\hline $2.42 \%$ & 1 & $0.01(-0.7152$ to 0.7352$)$ \\
\hline $5.60 \%$ & 1 & $0.6(0.2668$ to 0.9332$)$ \\
\hline $2.16 \%$ & 1 & $0.21(-0.574$ to 0.994$)$ \\
\hline $3.08 \%$ & I & $-0.02(-0.6276$ to 0.5876$)$ \\
\hline $2.96 \%$ & 1 & $0.68(0.0528$ to 1.3072$)$ \\
\hline $2.24 \%$ & 1 & $1.09(0.3256$ to 1.8544$)$ \\
\hline $4.15 \%$ & I & $1.43(0.9596$ to 1.9004$)$ \\
\hline $2.84 \%$ & 1 & $0.74(0.0932$ to 1.3868$)$ \\
\hline $2.96 \%$ & 1 & $0.59(-0.0372$ to 1.2172$)$ \\
\hline $100 \%$ & & $0.5558(0.4228$ to 0.6888$)$ \\
\hline
\end{tabular}

Figure S1.2 Forest plot of meta-analysis of RMET in MS compared to healthy controls 


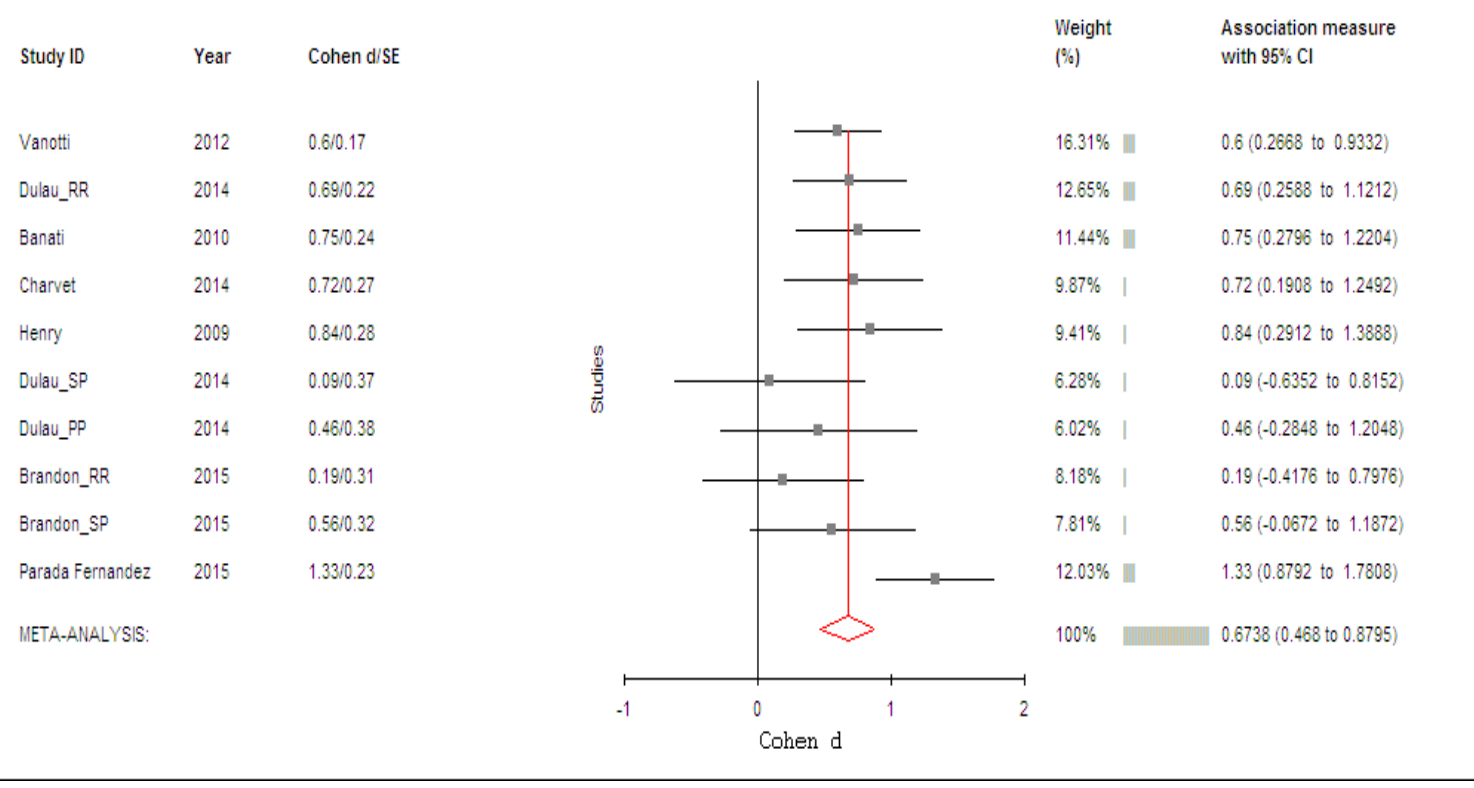

Figure S1.3 Forest plot of meta-analysis of ToM-PT in MS compared to healthy controls

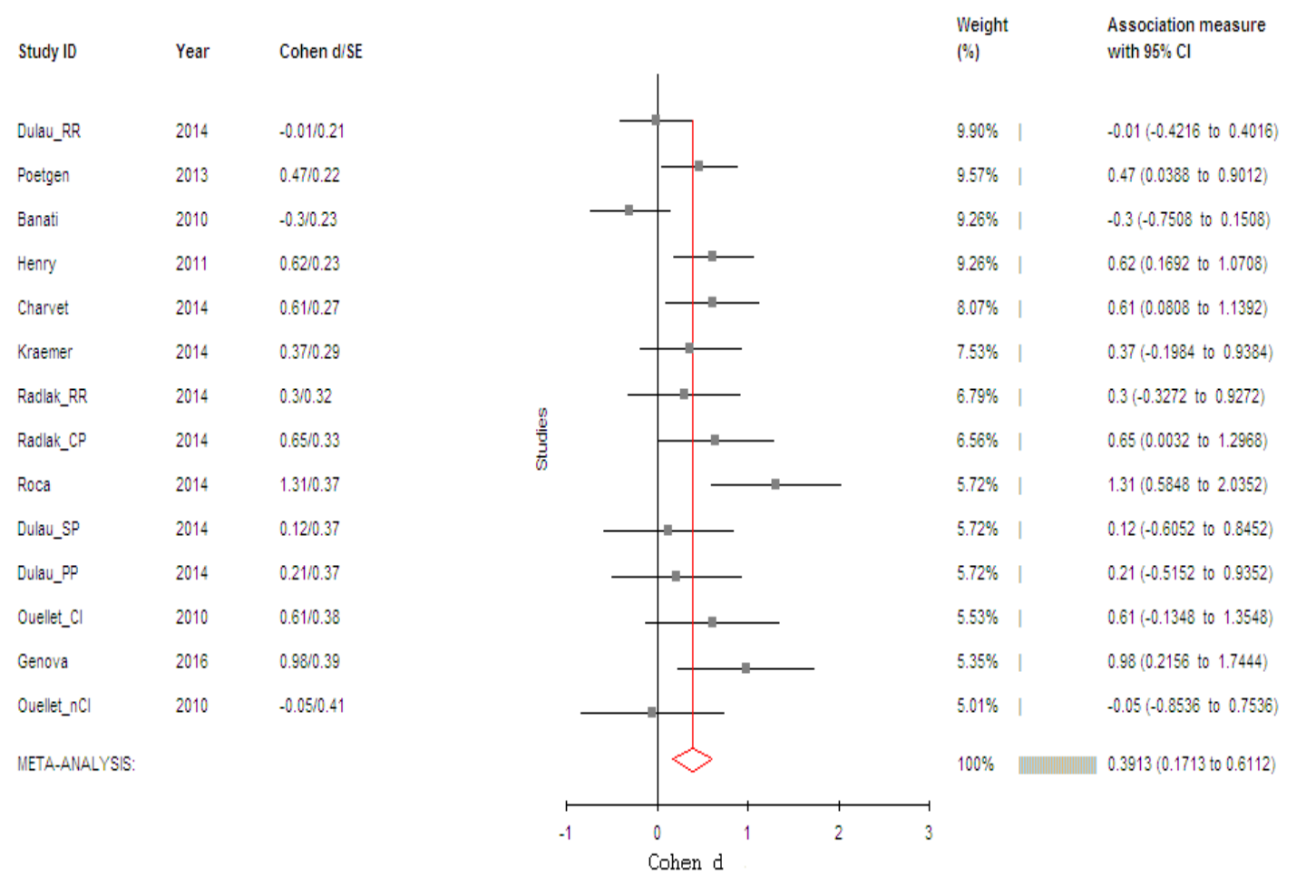

Figure S1.4 Forest plot of meta-analysis of recognition of fear in MS compared to healthy controls 


$\begin{array}{lll}\text { Study ID } & \text { Year } & \text { Cohen d/SE } \\ \text { Prochnow } & 2012 & 0.44 / 0.22 \\ \text { Henry } & 2011 & 1.08 / 0.23 \\ \text { Lenne } & 2014 & 0.67 / 0.26 \\ \text { Henry } & 2009 & 0.59 / 0.27 \\ \text { Jenna } & 2011 & 0.3 / 0.37 \\ \text { Di Bitonto } & 2011 & 0.16 / 0.4 \\ \text { Parada_Fernandez } & 2015 & 0.55 / 0.22 \\ \text { Radlak_CP } & 2014 & 0.22 / 0.33 \\ \text { Radlak_RR } & 2014 & 0.27 / 0.32 \\ \text { MiETA-ANALYSIS: } & & \end{array}$

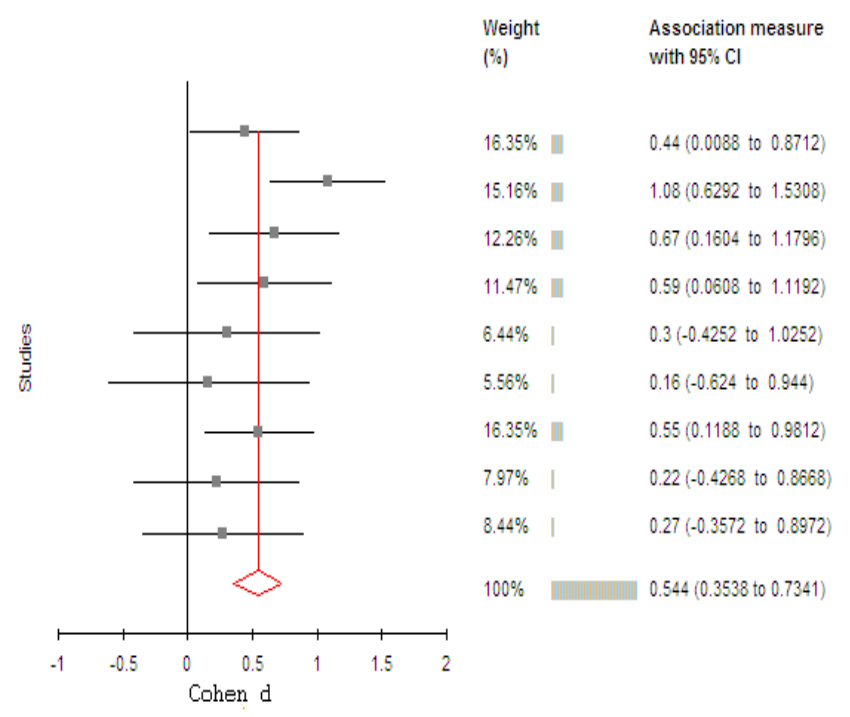

Figure S1.5 Forest plot of meta-analysis of recognition of anger in MS compared to healthy controls

$\begin{array}{lll}\text { Study ID } & \text { Year } & \text { Cohen d/SE } \\ & & \\ \text { Pinto } & 2012 & 0.15 / 0.19 \\ \text { Prochnow } & 2011 & 0.48 / 0.22 \\ \text { Henry } & 2011 & 0.98 / 0.23 \\ \text { Lenne } & 2014 & 0.56 / 0.26 \\ \text { Henry } & 2009 & 0.62 / 0.28 \\ \text { Jenna } & 2011 & -0.17 / 0.36 \\ \text { Di Bitonto } & 2011 & 0.41 / 0.4 \\ \text { Parada_Fernandez } & 2015 & 1.07 / 10.23 \\ \text { Radlak_CP } & 2014 & 0.88 / 0.34 \\ \text { Radlak_RR } & 2014 & 0.39 / 0.32 \\ \text { MiETA-ANALYYSIS: } & & \\ & & \end{array}$

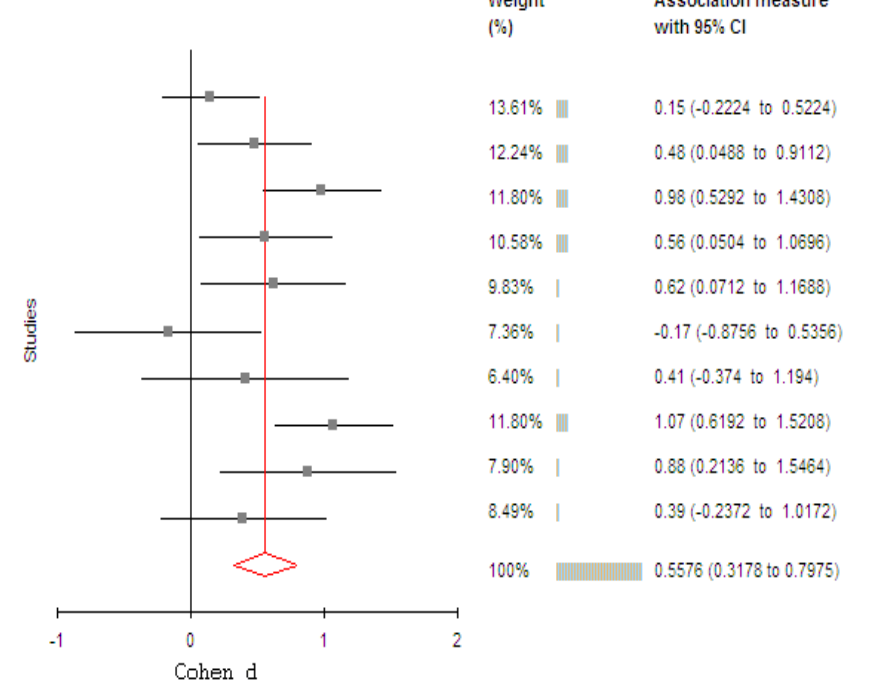

Figure S1.6 Forest plot of meta-analysis of recognition of disgust in MS compared to healthy controls 


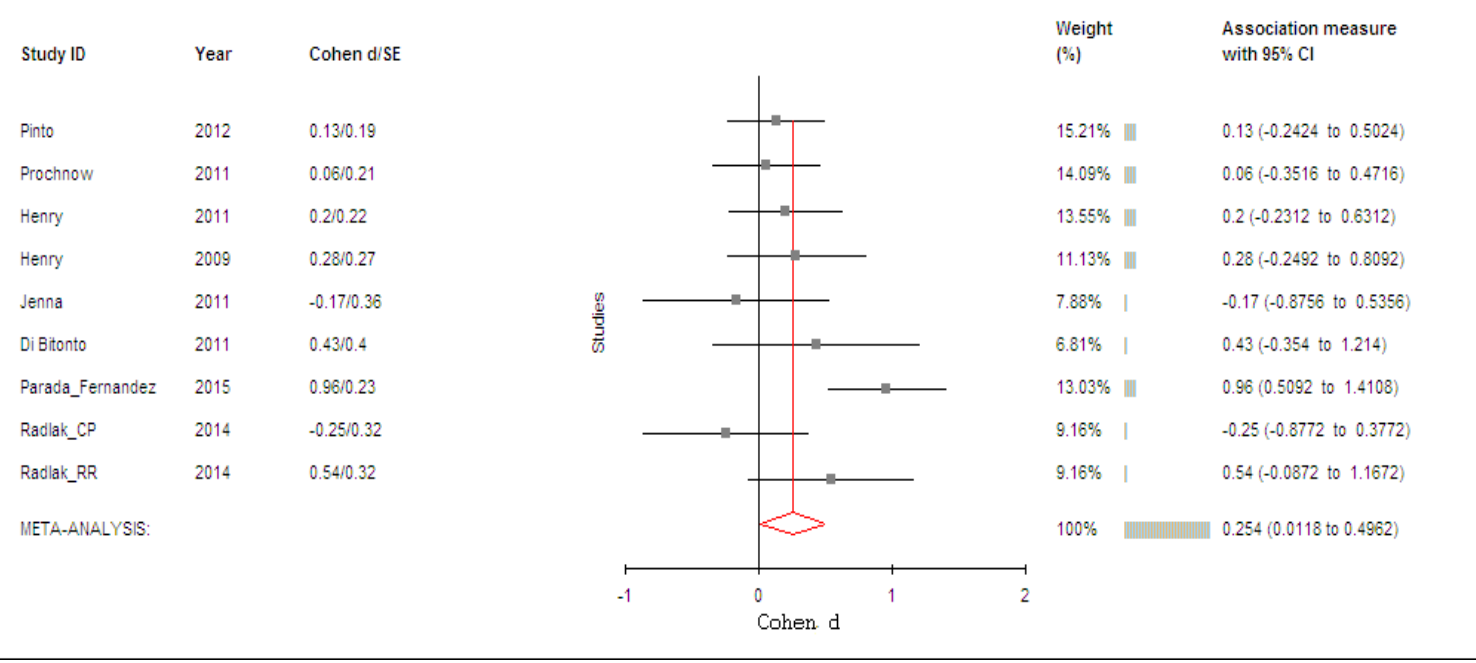

Figure S1.7 Forest plot of meta-analysis of recognition of sad faces in MS compared to healthy controls

$\begin{array}{lll}\text { Study ID } & \text { Year } & \text { AM[e]/SE[e] } \\ \text { Pinto } & 2012 & 0.25 / 0.19 \\ \text { Prochnow } & 2011 & 0.35 / 0.22 \\ \text { Henry } & 2011 & 0.08 / 0.22 \\ \text { Lenne } & 2014 & 0.7 / 0.27 \\ \text { Henry } & 2009 & 0.16 / 0.27 \\ \text { DiBitonto } & 2011 & 0 / 0.39 \\ \text { Parada_Fernandez } & 2015 & 0.67 / 0.23 \\ \text { Radlak_CP } & 2014 & 0.34 / 0.33 \\ \text { Radlak_RR } & 2014 & 0.19 / 0.32 \\ \text { MEETA-ANAL_YSIS: } & & \end{array}$
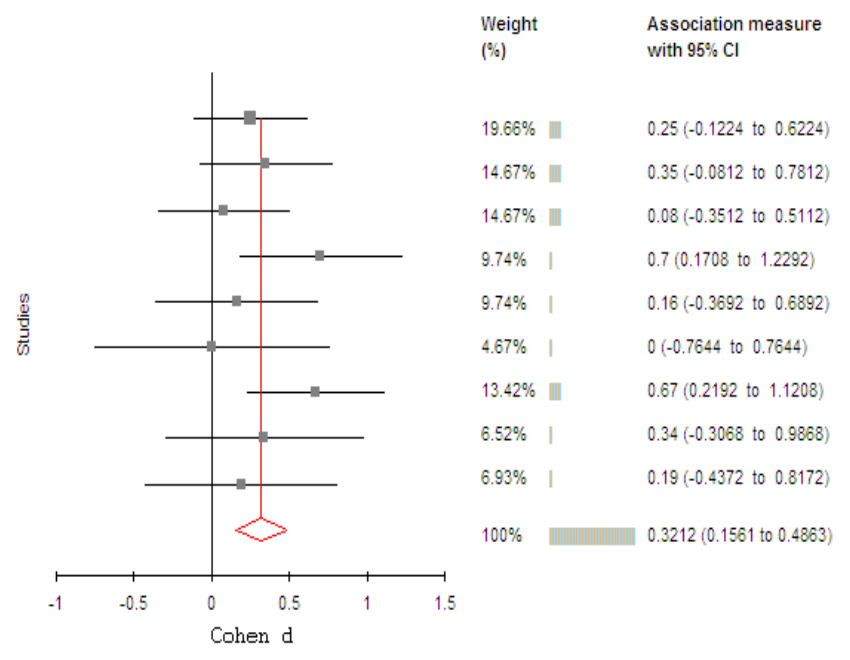

Figure S1.8 Forest plot of meta-analysis of recognition of surprise in MS compared to healthy controls 


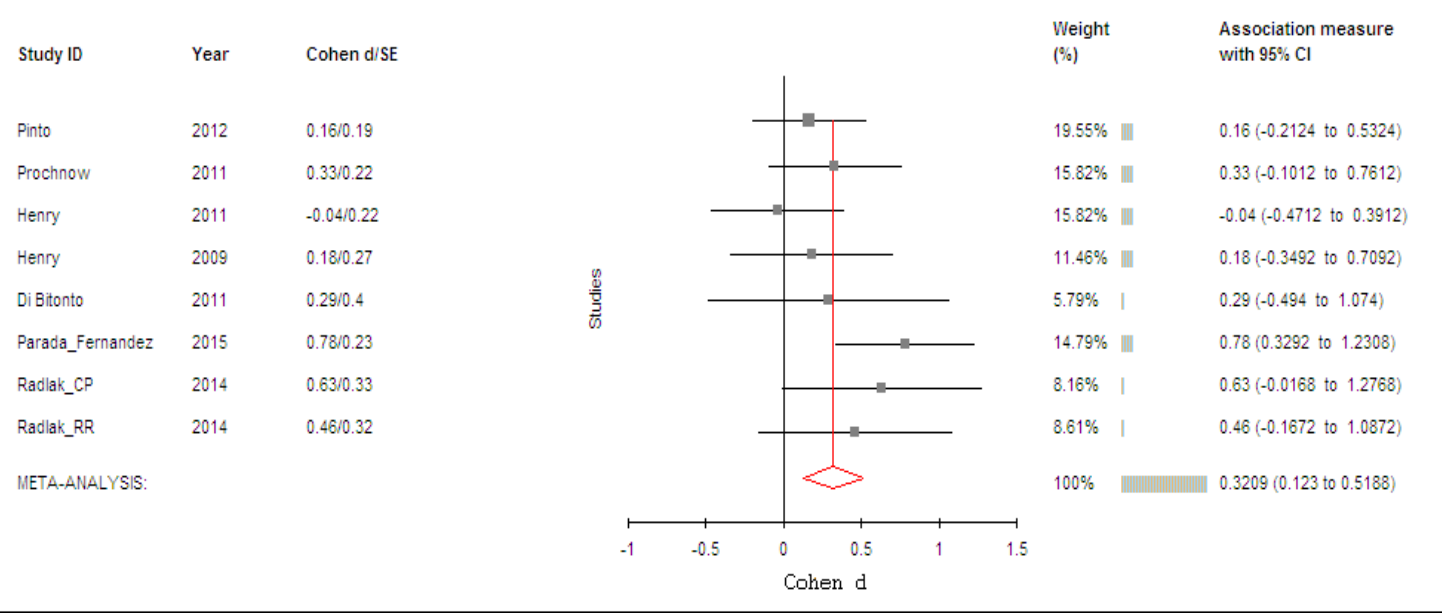

Figure S1.9 Forest plot of meta-analysis of recognition of happy faces in MS compared to healthy controls

$\begin{array}{lll}\text { Study ID } & \text { Year } & \text { Cohen d/SE } \\ \text { Pinto } & 2012 & 010.19 \\ \text { Prochnow } & 2011 & 010.21 \\ \text { Henry } & 2011 & 0.3220 .23 \\ \text { Lenne } & 2014 & 0.2550 .26 \\ \text { Henry } & 2009 & 0.3810 .27 \\ \text { Di Bitonto } & 2011 & 010.39 \\ \text { Parada_Fernandez } & 2015 & 0.5910 .23 \\ \text { Radlak_CP } & 2014 & 0.3110 .33 \\ \text { Radlak_RR } & 2014 & 0.1770 .32 \\ \text { META_ANALYYSIS: } & & \\ & & \end{array}$

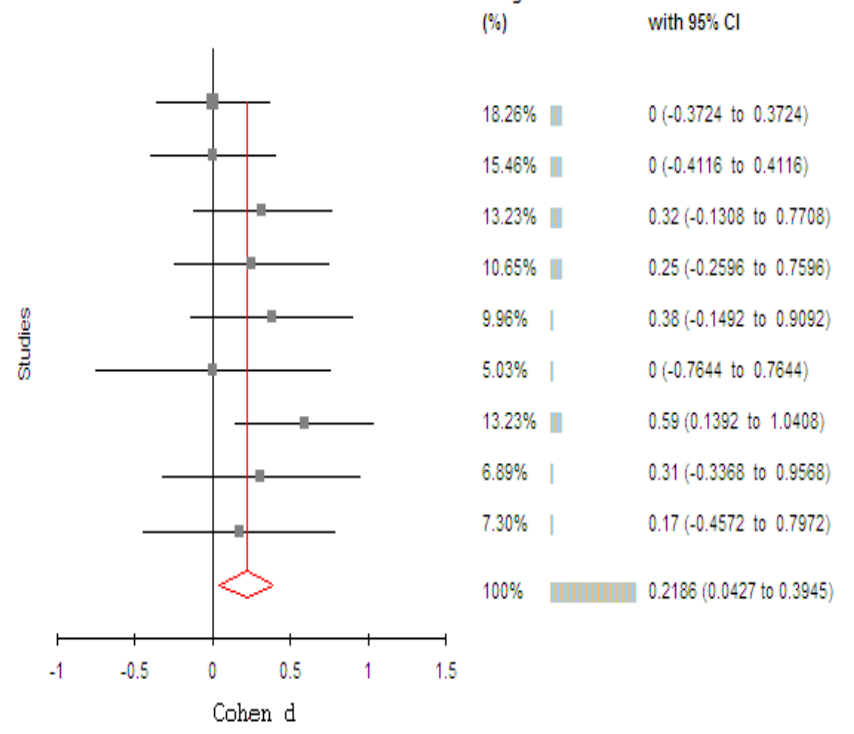

Figure S1.10 Forest plot of meta-analysis of social cognition in chronic progresive vs relapsing remitting $\mathrm{MS}$ 


$\begin{array}{lll}\text { Study ID } & \text { Year } & \text { Cohen d/SE } \\ \text { Dulalu_SP } & 2014 & -0.18 / 0.36 \\ \text { Brandon } & 2015 & 0.71 / 0.26 \\ \text { Bernesier } & 2014 & 1.31 / 0.35 \\ \text { Radlak } & 2014 & 0.18 / 0.27 \\ \text { Dulalu_PP } & 2014 & 0.06 / 0.37 \\ \text { META_ANALYSIS: } & & \end{array}$

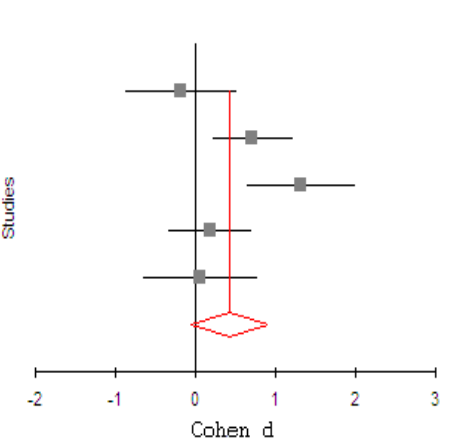

Weight Association measure

(\%) with $95 \% \mathrm{Cl}$

$18.40 \%$

$22.61 \%$ - $\quad 0.71(0.2004$ to 1.2196$)$

$18.80 \%$ - $1.31(0.624$ to 1.996$)$

$22.18 \% \square \quad 0.18(-0.3492$ to 0.7092$)$

$18.01 \%$ - $\quad 0.06(-0.6652$ to 0.7852$)$

$100 \%=0.4245(-0.0607$ to 0.9096$)$

META-ANALYSIS: 
Social cognition in multiple sclerosis: a meta-analysis

Emre Bora ${ }^{1}$, Serkan Özakbaş ${ }^{2}$, Dennis Velakoulis ${ }^{1}$, Mark Walterfang ${ }^{1,3}$

Supplement-2 Funnel plots of meta-analyses of social cognition measures in MS in comparison to healthy controls

Figure S2.1 Funnel plot for meta-analysis of total emotion recogniton

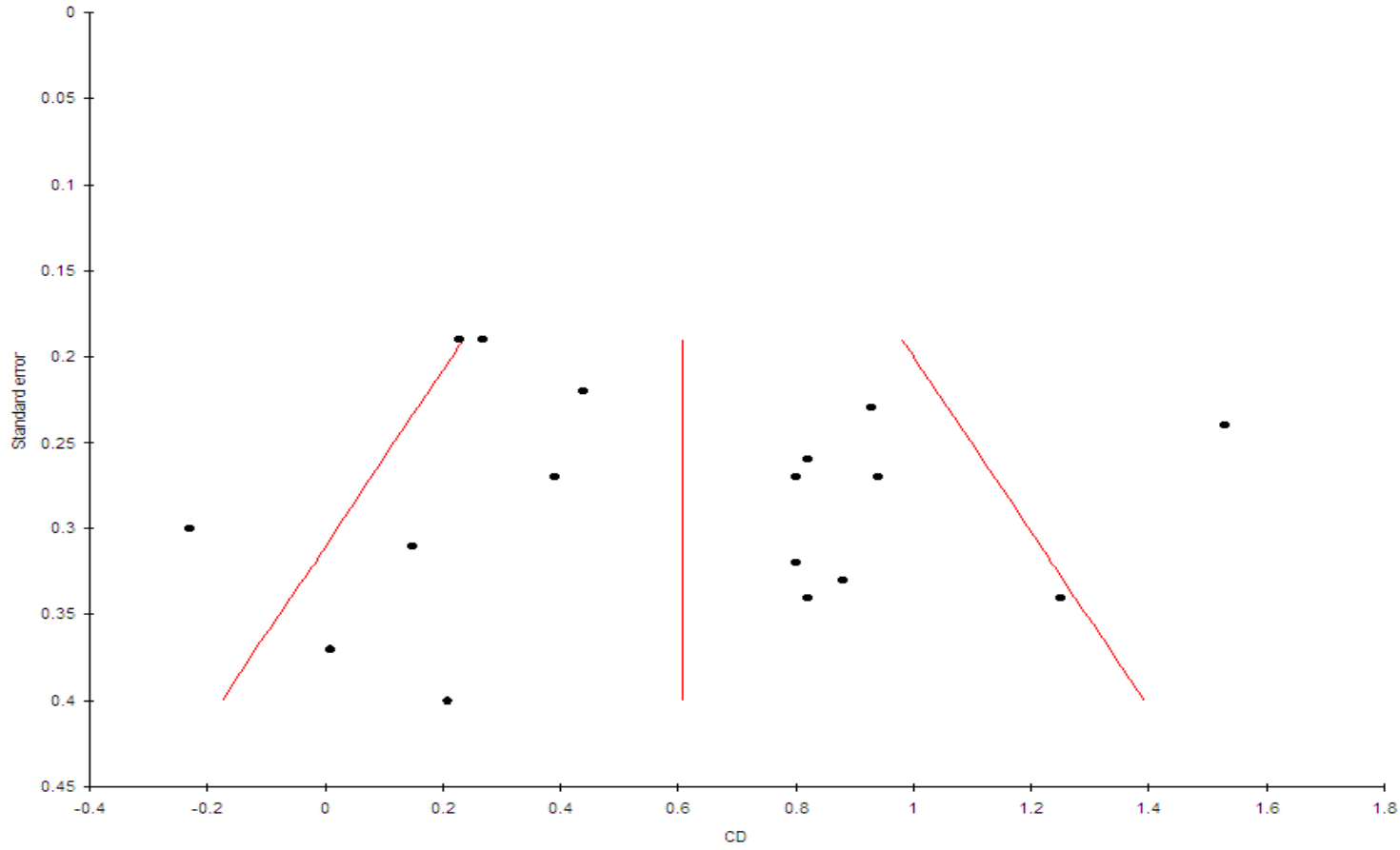

Figure S2.2 Funnel plot for meta-analysis of ToM

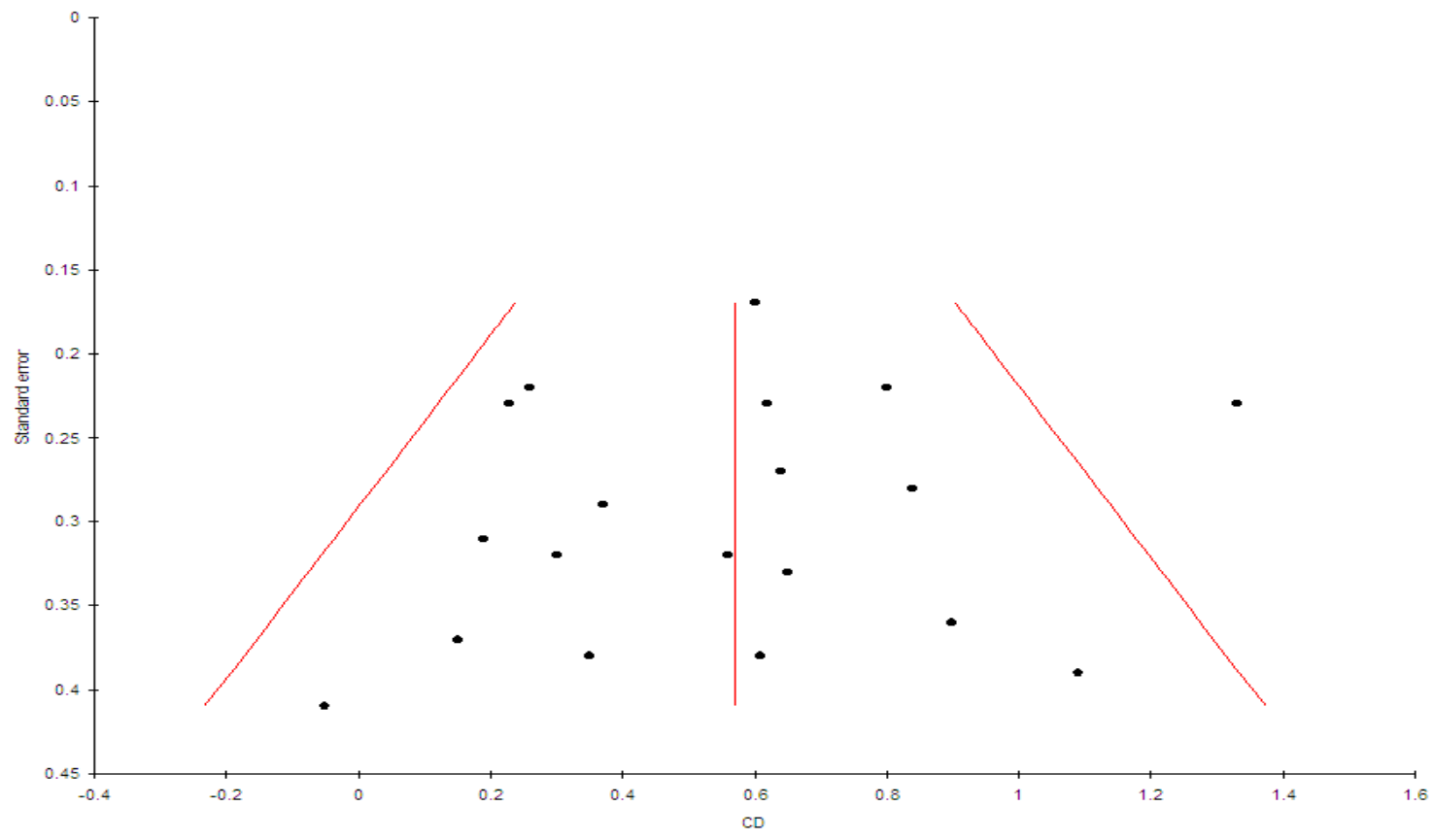

Figure S2.3 Funnel plot for meta-analysis of pooled social cognition score 


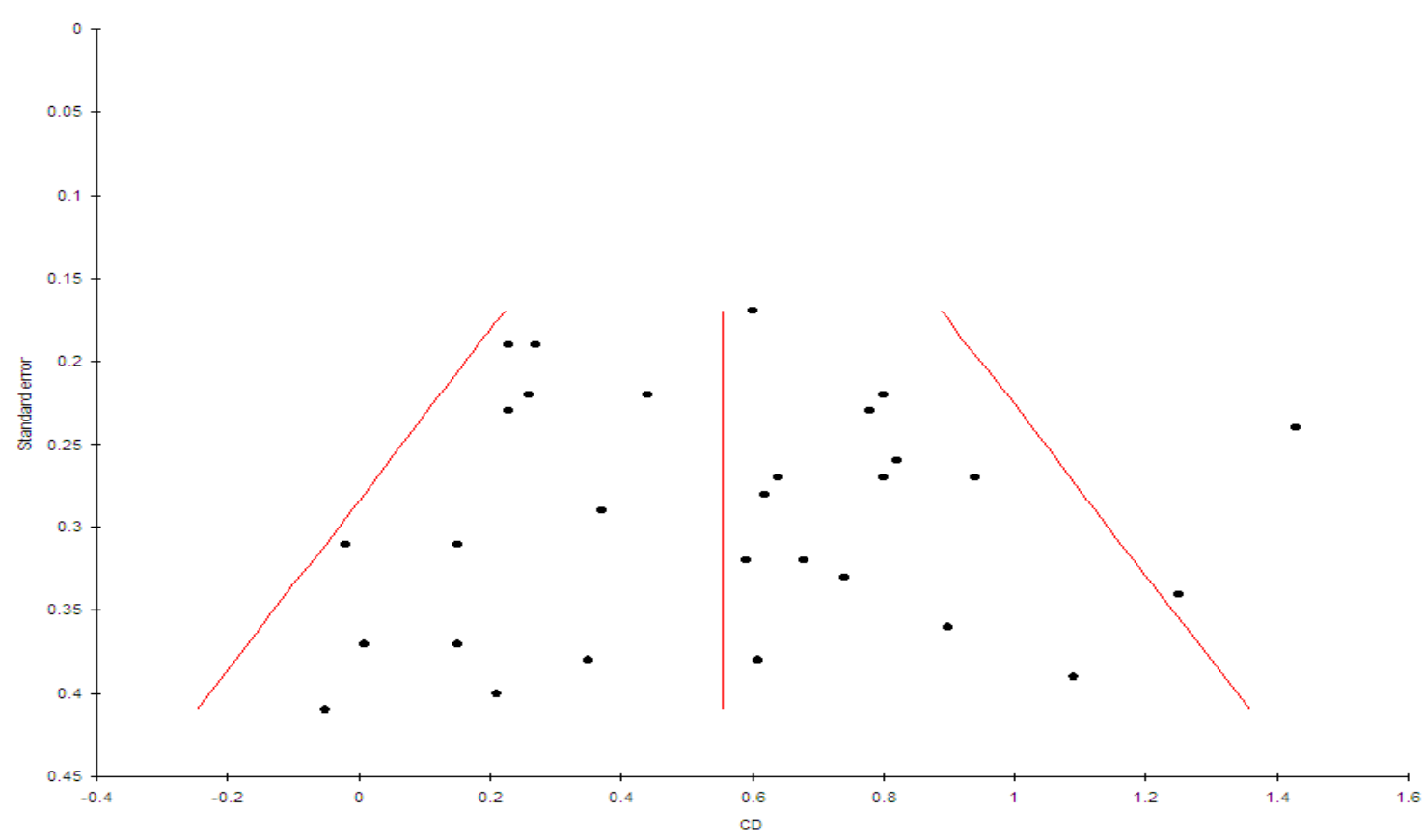

Figure S2.4 Funnel plot for meta-analysis of RMET

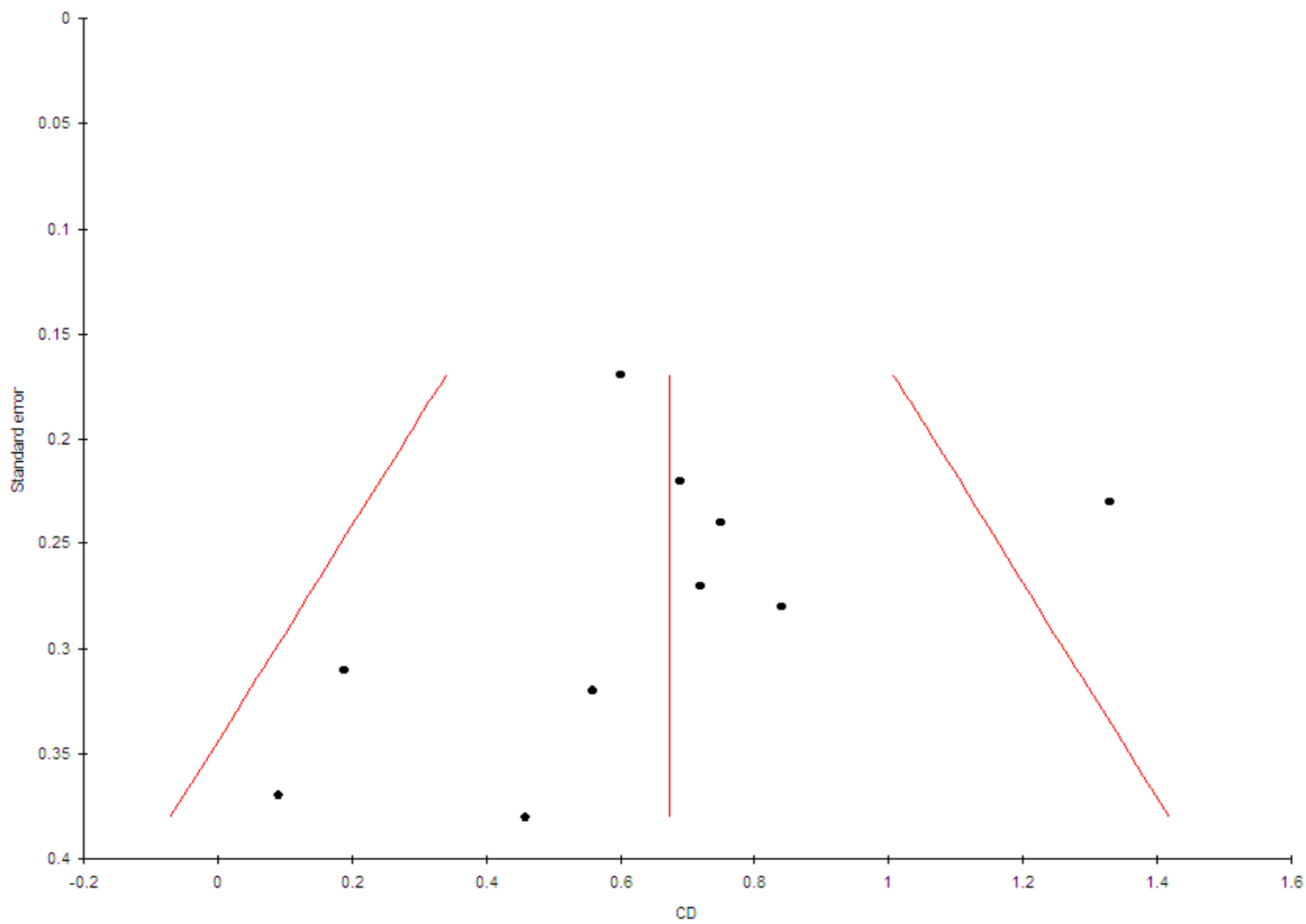

Figure S2.5 Funnel plot for meta-analysis of ToM-PT 


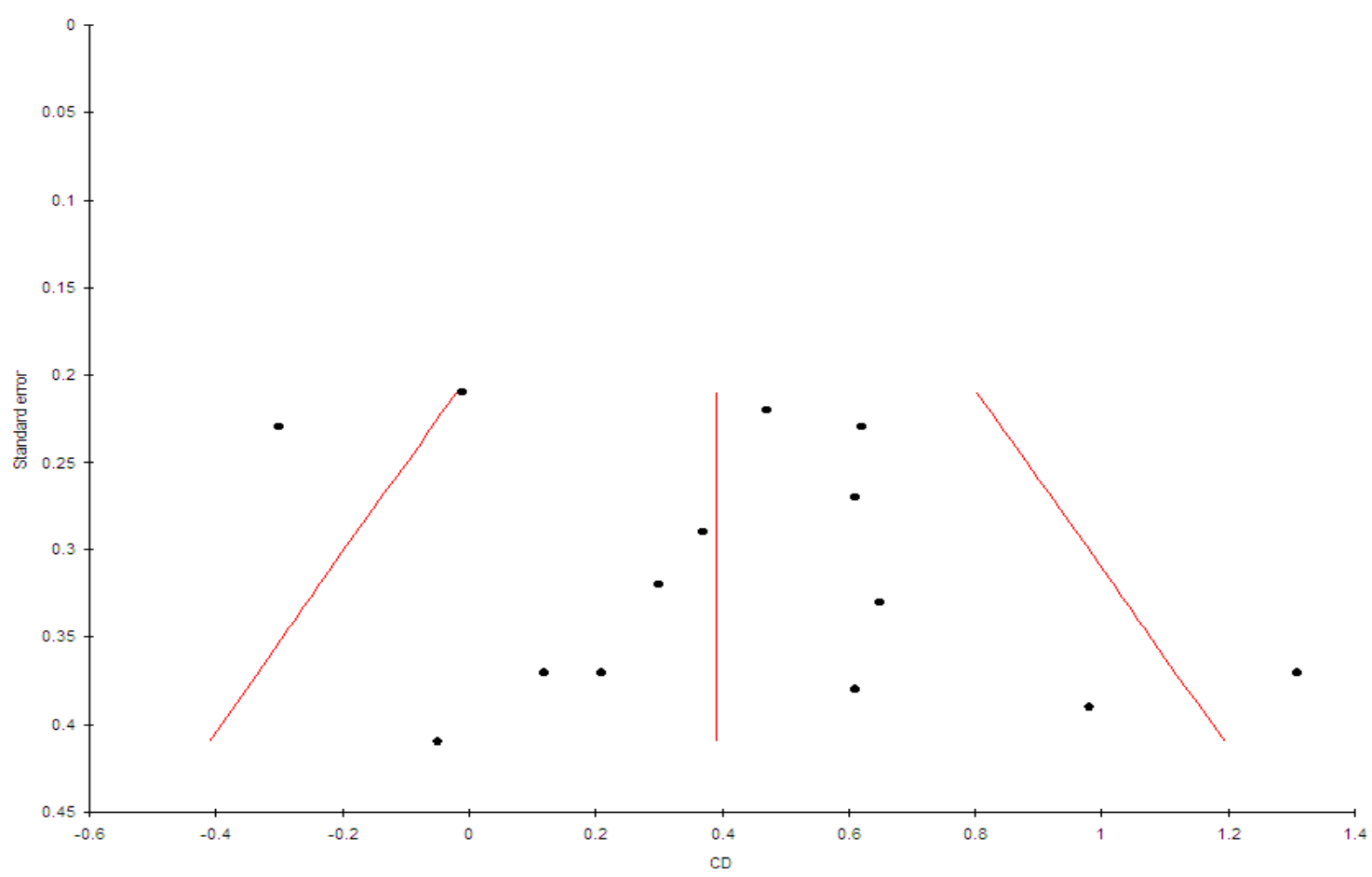

Figure S2.6 Funnel plot for meta-analysis of faux pas recognition test

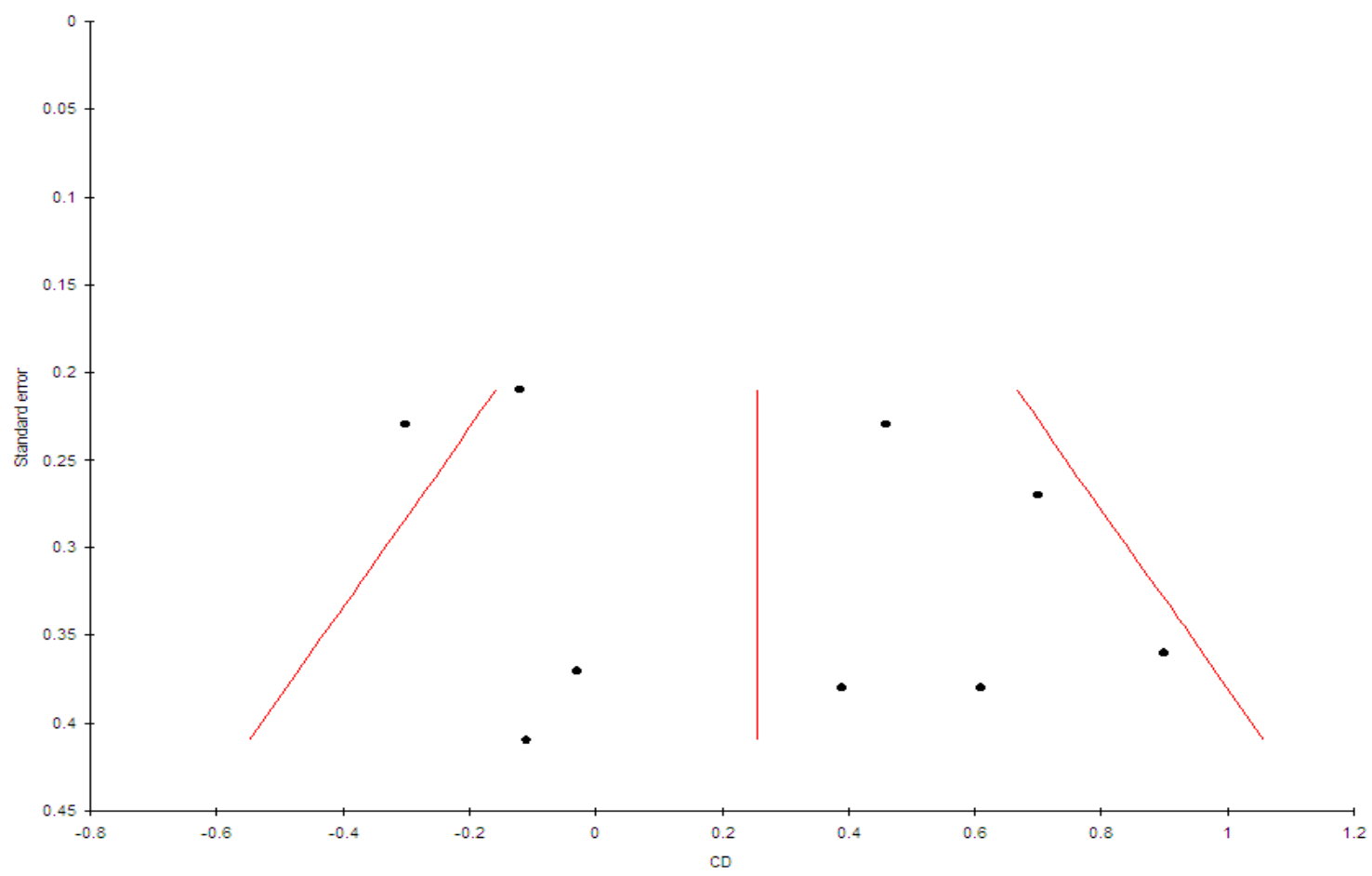

Figure S2.7 Funnel plot for meta-analysis of facial fear recognition 


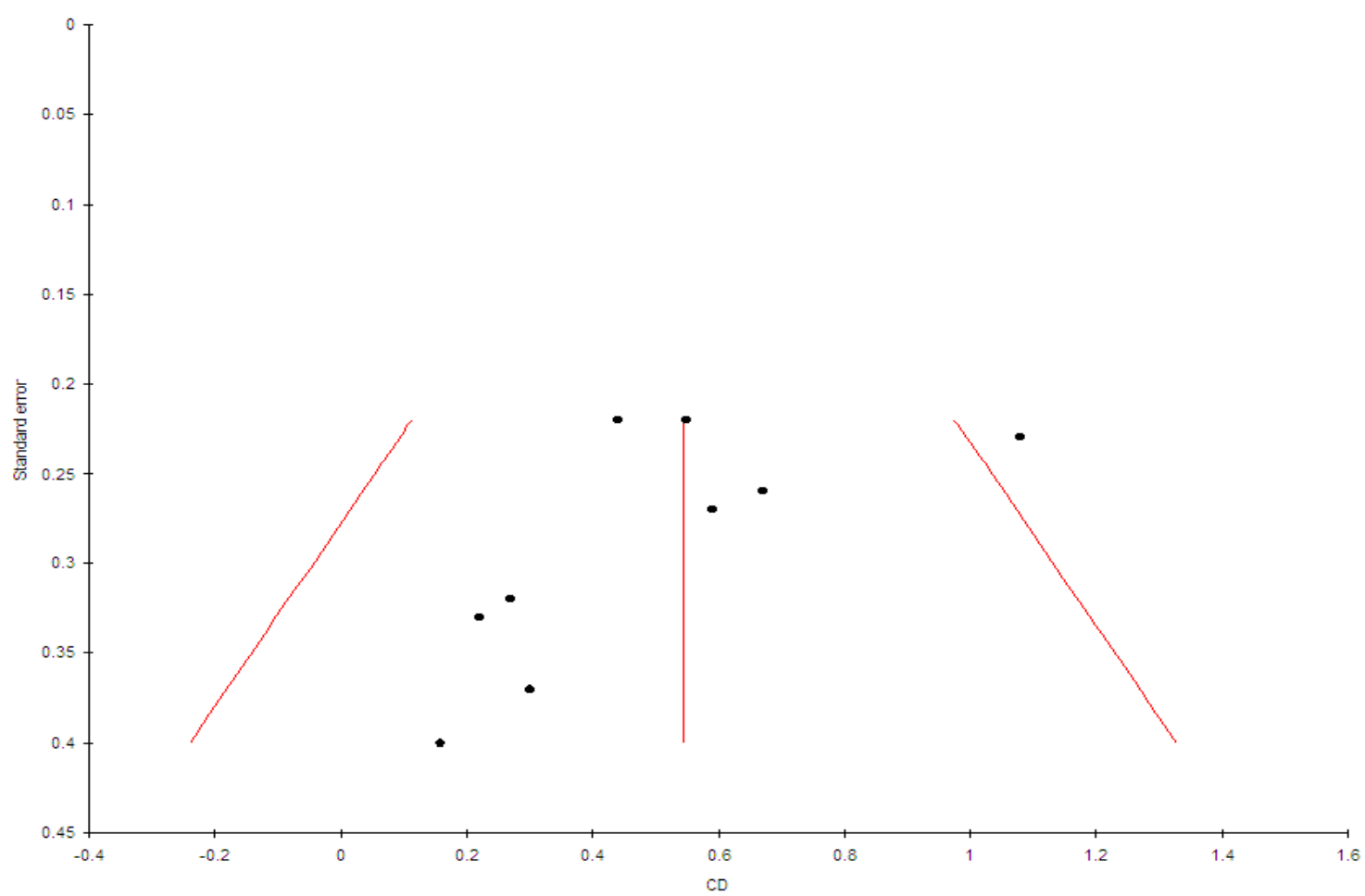

Figure S2.8 Funnel plot for meta-analysis of recognition of angry faces

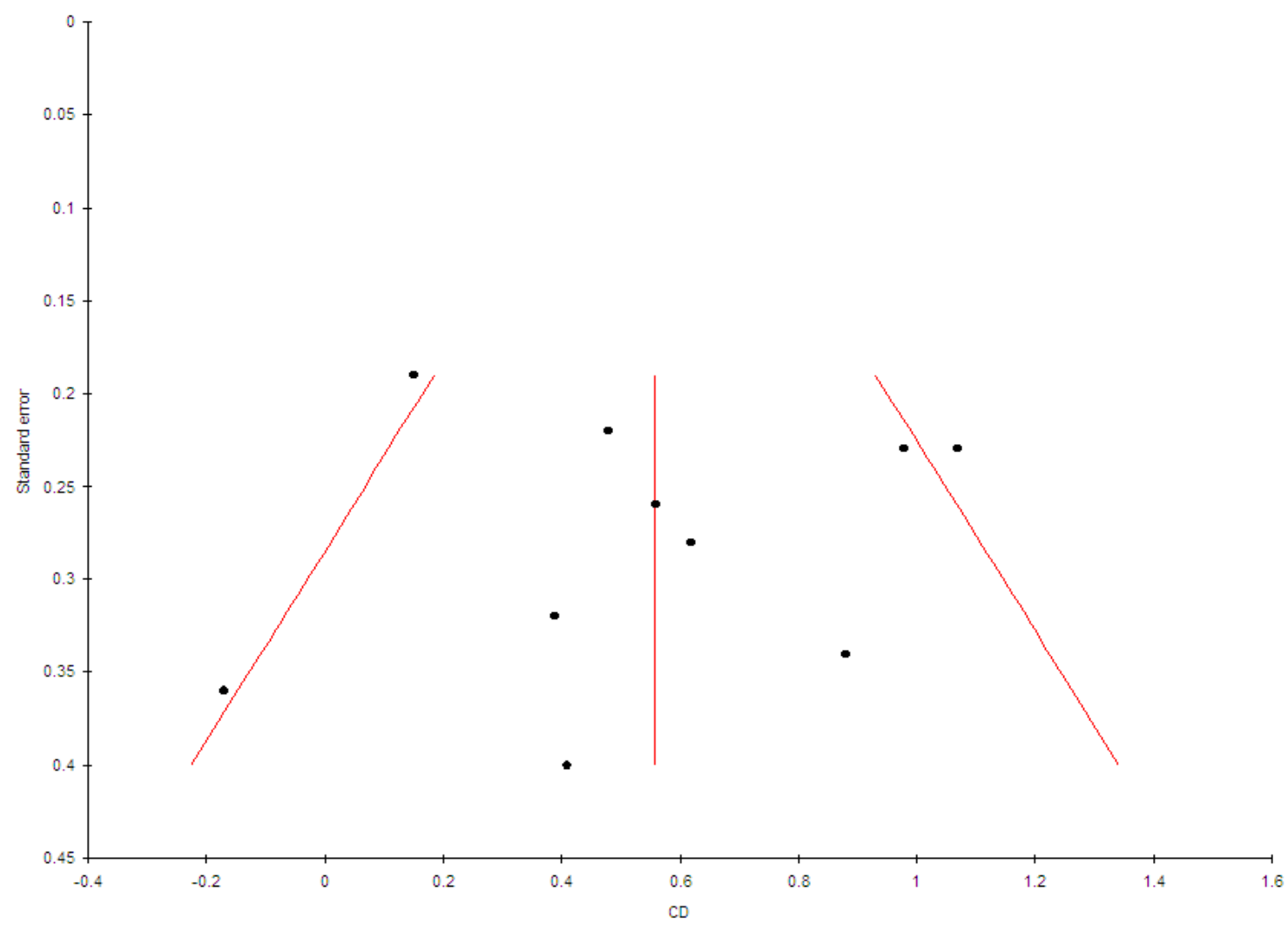

Figure S2.9 Funnel plot for meta-analysis of facial disgust recognition 


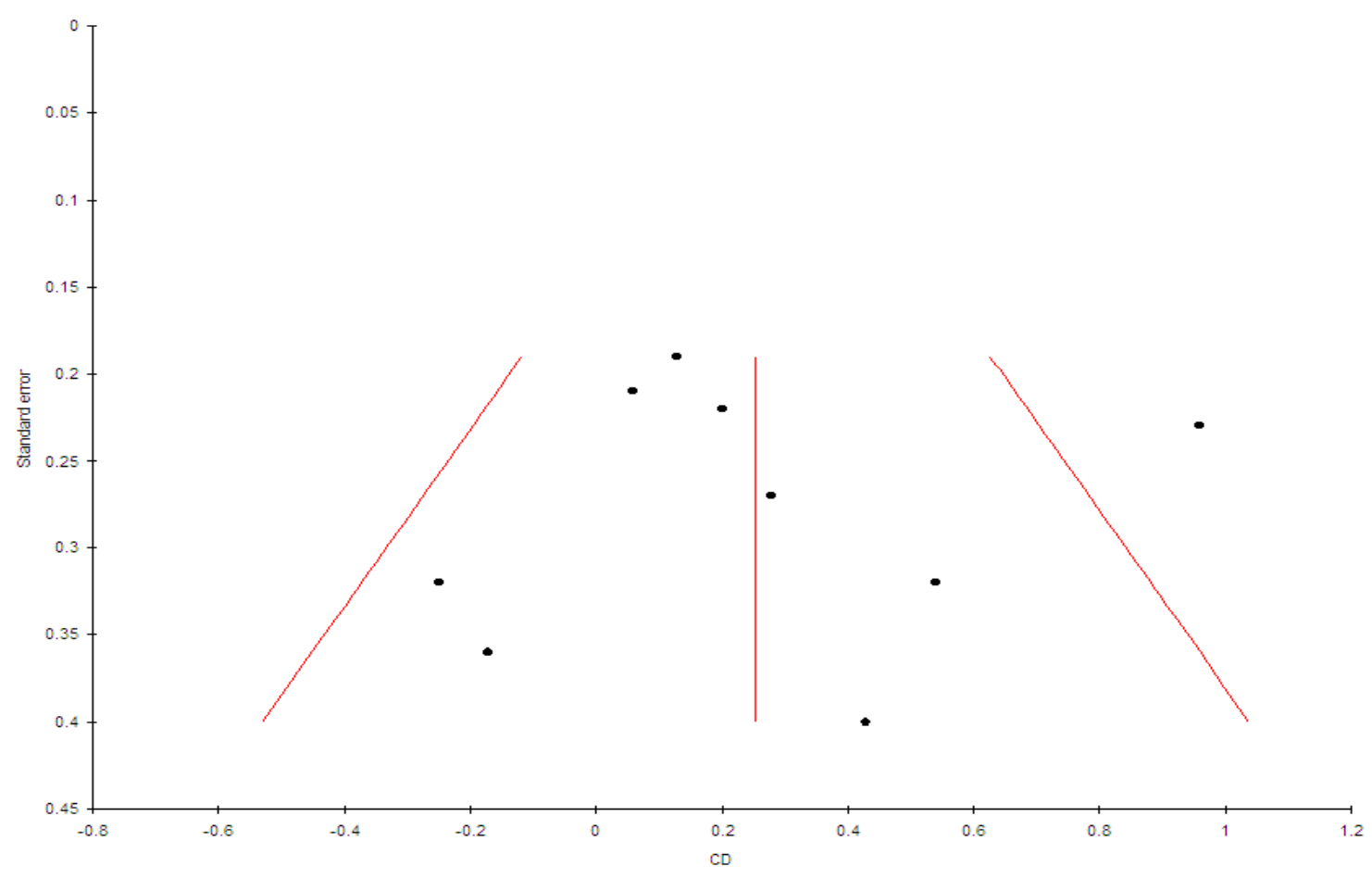

Figure S2.10 Funnel plot for meta-analysis of recognition sad faces

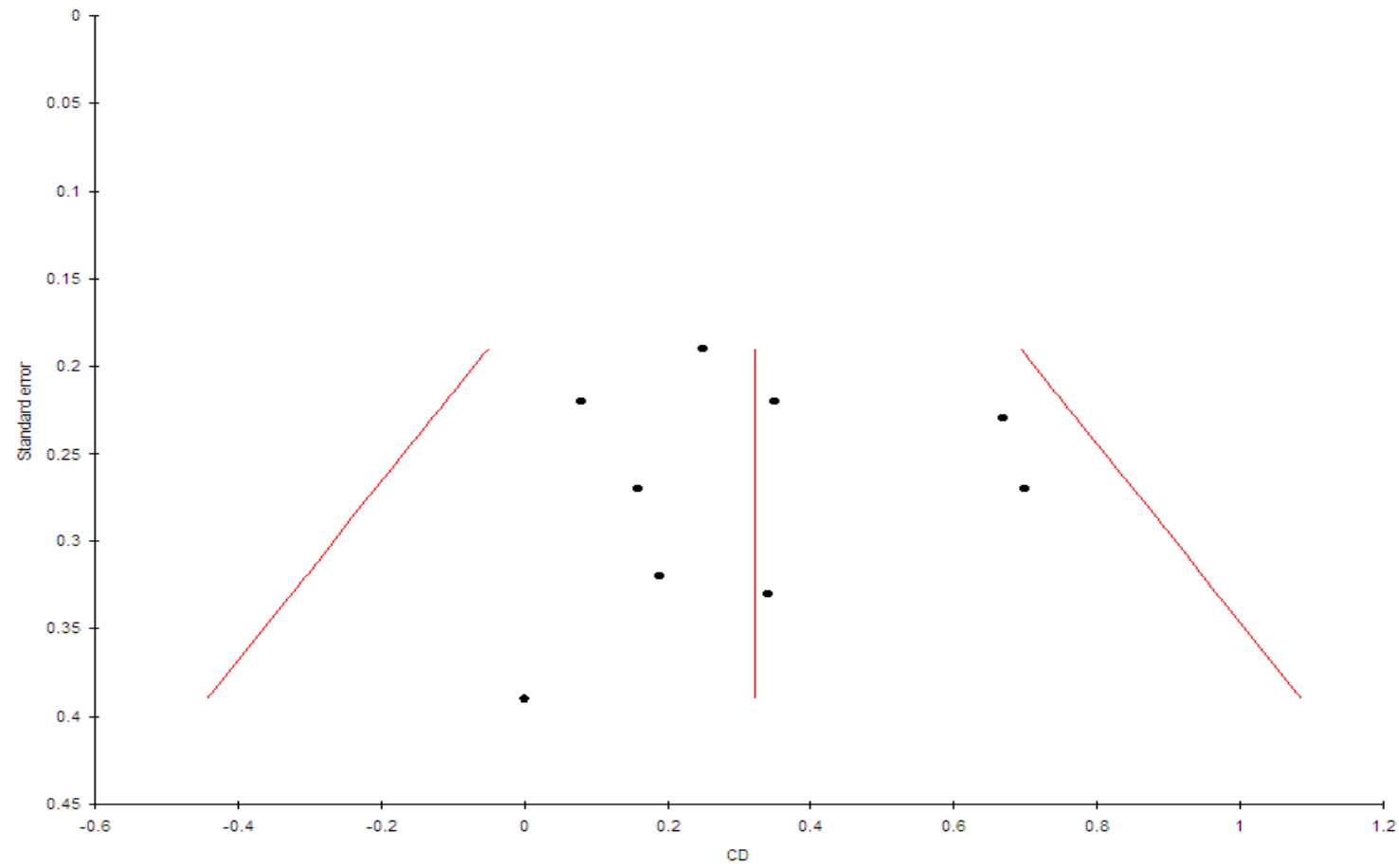

Figure S2.11 Funnel plot for meta-analysis of facial surprise recognition 


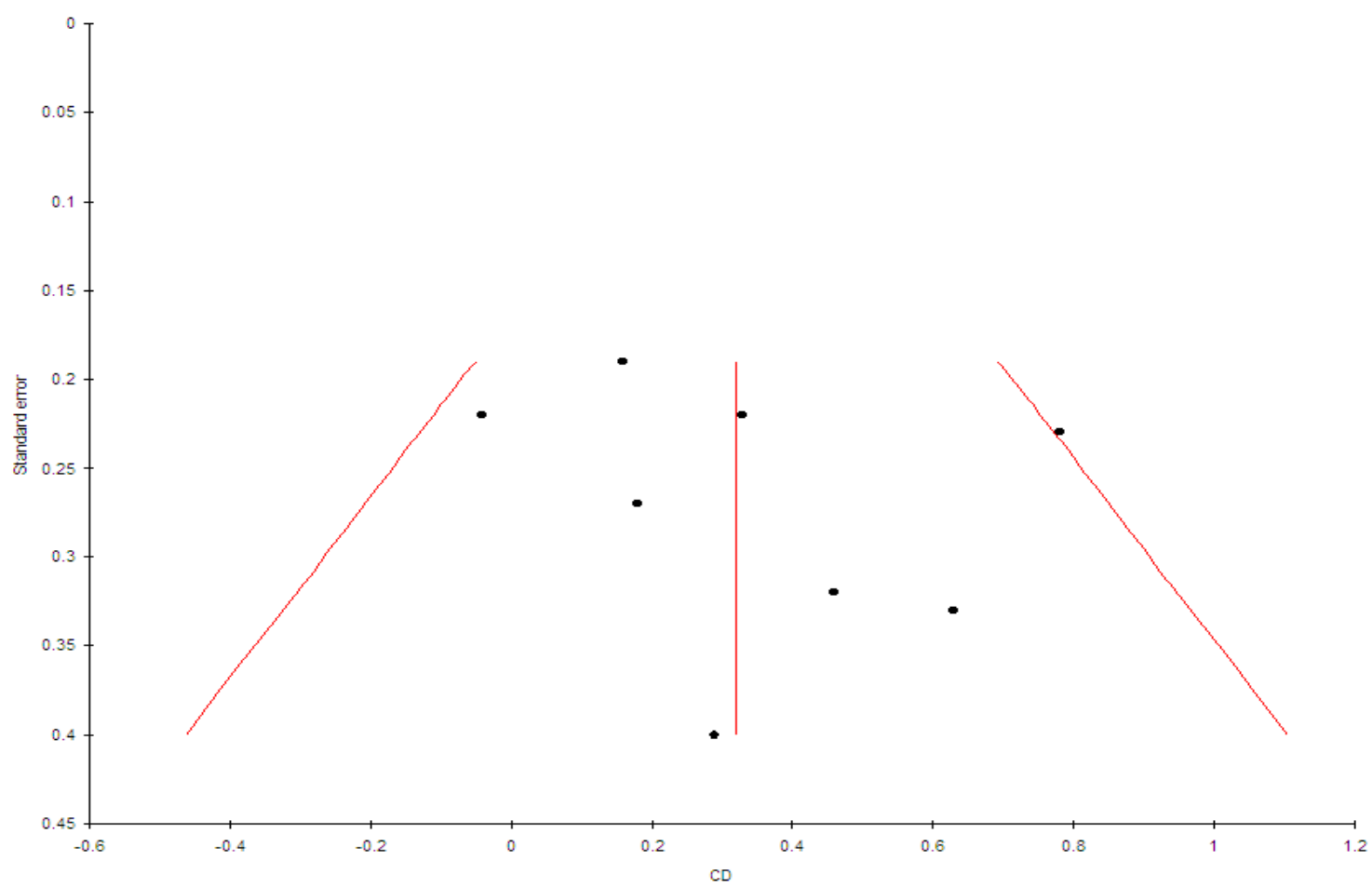

Figure S2.12 Funnel plot for meta-analysis of recognition of happy faces

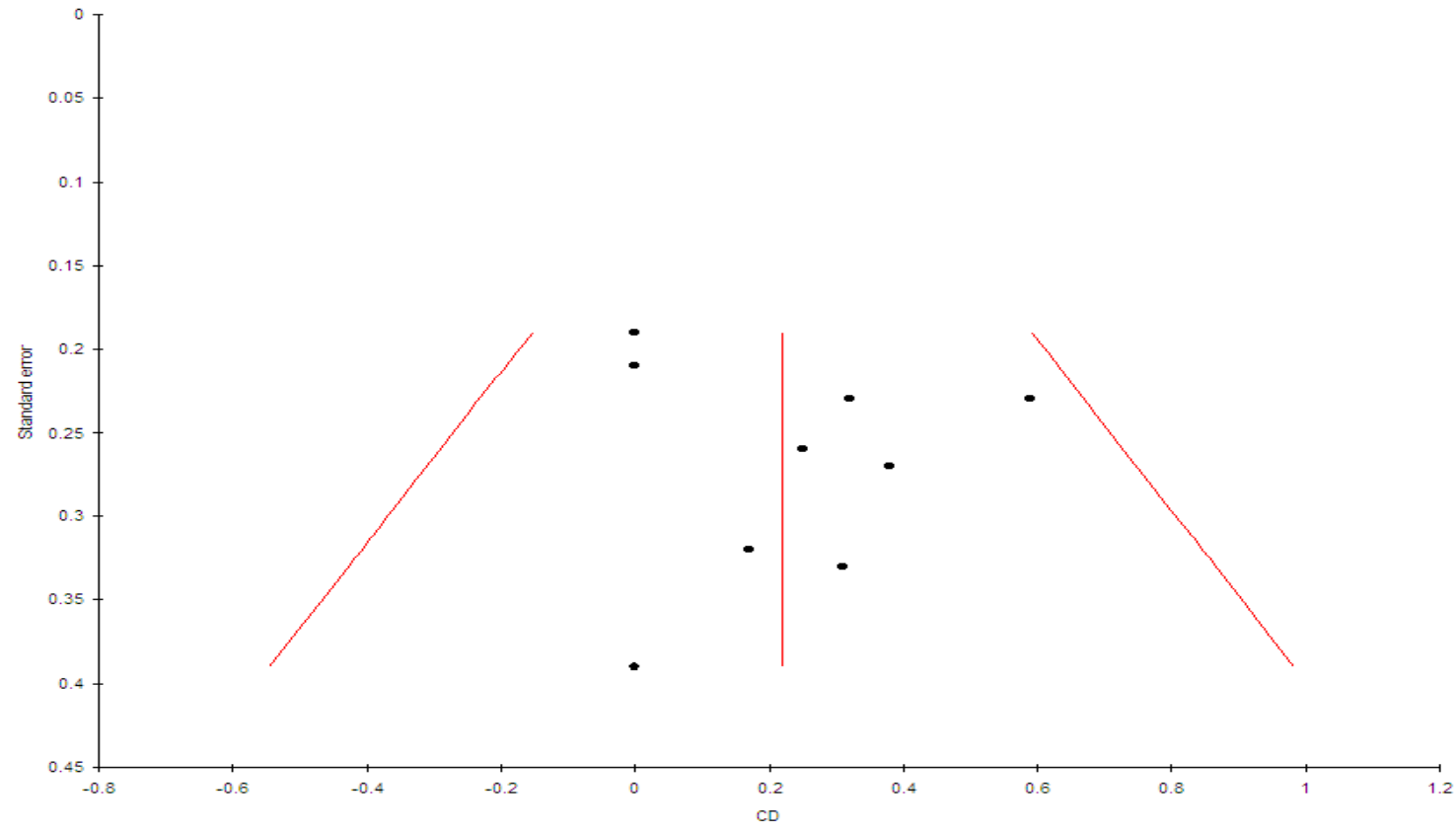

